\title{
Gender role attitudes cannot explain how British couples responded to increased housework demands during the COVID-19 pandemic
}

\author{
Ansgar Hudde ${ }^{\bowtie}$, Karsten Hank \& Marita Jacob \\ ISS - University of Cologne \\ ${ }^{\otimes}$ hudde@wiso.uni-koeln.de \\ - Last modified: November 2021 - \\ Forthcoming in Socius
}

\begin{abstract}
:
Previous research has shown that gender role attitudes can predict changes in couples' housework division over critical life events, but these studies might have suffered from endogeneity because such life events are anticipated and may be affected by gender role attitudes. In contrast, the COVID-19 pandemic was a truly exogenous shock that hit couples unexpectedly. Estimating fixed-effects regression models, we examine the role of gender ideologies in how couples adjusted their division of housework during the COVID-19 pandemic in 2020 compared to a pre-pandemic baseline observation. The data cover 3,219 couples from the UK Household Longitudinal Study. Both partners spent substantially more time on housework throughout the COVID-19 crisis than before, especially in the early stages. However, we found no evidence that individuals' or couples' pre-crisis gender role attitudes affected changes in men's and women's absolute or relative contributions to housework at any time during the lockdown.
\end{abstract}

\section{Key words:}

Housework; Gender role attitudes; Gender inequality; Gender ideology; COVID-19; Corona. 


\section{Introduction}

The gendered division of labour is embedded in a broader system of gender inequalities and is thus more than just a family affair (e.g., Fuwa 2004). Importantly, despite some indication of convergence at older ages, the division of housework in couples remains highly gendered throughout the life course (e.g., Horne et al. 2018; Leopold et al. 2018). A growing body of research indicates, however, that critical life events are often accompanied by subsequent adaptations of couples' division of domestic work: Principal examples are family-related events, such as the transition to marriage or parenthood (e.g., Baxter et al. 2008; Kühhirt 2012; Schober 2013a), as well as employment-related events, such as transitions to full-time work (e.g., Gershuny et al. 2005; Schober 2013b), unemployment (e.g., Fauser 2019; van der Lippe et al. 2018), or retirement (Leopold \& Skopek 2018; Szinovacs 2000). Studies provide robust evidence that changes in partners' relative resources and time availability cannot fully account for the observed adaptations in the division of household labour (for a review see LachanceGrzela \& Bouchard 2010). Rather, and in line with gender construction theories (e.g., Geist \& Ruppaner 2018), it has been suggested that partners' gender role attitudes are central to any explanation (e.g., Carriero \& Todesco 2018). Gender role attitudes (or, synonymously, gender ideologies) are "beliefs about the appropriate role activities for women and men" in various life spheres, such as work, family, or politics (McHugh \& Frieze 1997: 4).

Gender ideologies are, however, to some extent endogenous to the previously studied events: Holding more traditional attitudes is, for example, likely to affect the risk of unemployment and the timing of retirement (through its effect on male and female partners' labour force participation; e.g., Uunk \& Lersch 2019), and (dis)similarities in gender role attitudes have been shown to affect couples' fertility (e.g., Hudde \& Engelhardt 2020). To avoid possible bias due to such endogeneity, assessments of gender ideologies' role in adaptations of couples' division of housework following critical life events should ideally draw on truly exogenous shocks - such as the COVID-19 pandemic. 
The COVID-19 crisis of 2020 hit families unexpectedly. A key concern in debates about the consequences of the COVID-19 pandemic is its potential impact on gender inequalities (e.g., Alon et al. 2020; Oreffice \& Quintana-Domeque 2020). Some commentators have suggested that the virological pandemic might have triggered a 'patriarchal pandemic' (Chemaly 2020), disproportionally forcing women out of the labour market (e.g., Andrew et al. 2020; Reichelt et al. 2021) and back into traditional homemaker roles. This would not only bring to a halt recent macro-level trends of convergence in male and female partners' time spent on housework (e.g., Leopold et al. 2018; Pailhé et al. 2021) but can also be perceived as an unanticipated shock at the micro-level of couple relationships, forcing partners to renegotiate everyday routines, including their division of domestic labour.

The present study aims to deepen our understanding of the effect on gender role attitudes on the sharing of housework. To do so, we investigate whether and how pre-crisis gender role attitudes affected couples' reaction to the consequences of the pandemic and lockdowns. Our focus is on (1) housework tasks, such as cooking, cleaning, and doing the laundry, which should be studied as distinct from childcare (Sullivan 2013; note that our data do not allow a consistent measurement of couples' division of childcare over time) and (2) attitudes towards the gendered organization of family life because these attitudes and the agreement on the division of partners' tasks and responsibilities are directly related to the internal functioning of the relationship and family (Kalmijn 2005). We employ unique data from the UK Household Longitudinal Study and four waves of its COVID-19 panel survey (see Burton et al. 2020) to run fixed-effects regression models allowing us to monitor couples' adaptation from April through September 2020.

\section{COVID-19, couples' division of housework, and gender role attitudes}

Research on changes in couples' division of labour early in the COVID-19 crisis indicates that the amount of unpaid domestic and care work has increased for both women and men, but the 
relevant studies provide ambiguous evidence regarding changes in the gender gap across a range of European countries (e.g., Del Boca et al. 2020; Fodor et al. 2021; Hank \& Steinbach 2021; Hipp \& Bünning 2021). Evidence from the United Kingdom consistently shows that, on average, women have made substantially larger contributions to additional housework demands than men (see Andrew et al. 2020; Xue \& McMunn 2020; Zamberlan et al. 2021). Importantly, gender differences in the allocation of domestic work cannot be fully explained by gender differences in employment or earnings (Andrew et al. 2020; Zamberlan et al. 2021). ${ }^{1}$

To explain these dynamics in couples' division of domestic duties during the COVID-19 pandemic, two primary pathways related to changes in partners' time availability and additional housework demands have been discussed so far (see, for example, Hank \& Steinbach 2021). First, during the COVID-19 crisis, changes in employment affected partners' availability in the household. During the early phase of the pandemic, employment decreased considerably, and women were more likely than men to reduce their working hours or lose their jobs (e.g., Andrew et al. 2020; Reichelt et al. 2021; see, in contrast, Knize et al. 2021). Whereas unemployment or reductions in working hours have been shown to be associated with overall increases in housework time, there are important gender differences in couples' adjustment to reduced or terminated employment (e.g., Fauser 2019; Pailhé et al. 2019; van der Lippe et al. 2018): Task specialization by gender becomes more pronounced, and the extra domestic work is substantially greater for unemployed women than for unemployed men. This has been proposed as a likely driver of increases in women's share of household labour during the COVID-19 pandemic (e.g., Zamberlan et al. 2021). In parallel, however, for many of those who remained in employment, working conditions changed substantially. Working from home, for example, has become more common (e.g., Felstead \& Reuschke 2020). For men working from home,

\footnotetext{
${ }^{1}$ For investigations of the division of domestic labour in UK couples before the outbreak of the COVID19 pandemic, see, for example, Crompton et al. (2005), McMunn et al. (2020).
} 
previously invisible housework may have become more noticeable, and they may have become more involved in these tasks if their work area is shared with other family members and used for other purposes, e.g., as the dining table. Hence, for men in particular, this situation creates new opportunities and demands to increase their contribution to managing the household (e.g., Stenpaß \& Kley 2020).

Second, under lockdown, the amount of housework may have changed. People not only spent more time at home but also spent more time doing housework (e.g., Oreffice \& QuintanaDomeque 2020). At the same time, opportunities for domestic outsourcing - such as dining out or hiring household help - decreased. This is a likely driver of disproportionate increases in female partners' time devoted to household labour, as women have been shown to be the main beneficiaries of domestic outsourcing (e.g., Craig et al. 2016; Raz-Yurovich \& Marx 2019). Moreover, if mothers carry the main burden of new or resumed responsibilities resulting from closures of childcare facilities and schools (e.g., Benzeval et al. 2020; Zoch et al. 2021), one may expect spill-over effects on other tasks at home as well.

A third process of adaptation, which - to the best of our knowledge - has not yet been explicitly investigated in the context of the COVID-19 crisis, relates to gender role attitudes. This gap in previous research seems unfortunate because gender differences in the allocation of domestic work under lockdown cannot be fully explained by gender differences in employment rates or earnings (e.g., Andrew et al. 2020; Zamberlan et al. 2021). We argue that gender role attitudes predict how couples adjusted to the COVID-19 shock and the associated increased demands in housework.

Individuals with less egalitarian attitudes favour 'separate spheres,' where women's responsibilities revolve around the private realm, family, and homemaking, as opposed to men's responsibilities, which are mainly in the labour market and public sphere. Individuals with more egalitarian attitudes ascribe to the idea of 'joint spheres,' in which women and men are equally involved in tasks in all spheres, such as family, housework, and the labour market (see Davis 
\& Greenstein 2009). Consequently, those with more egalitarian attitudes should favour equal involvement of women and men in housework, whereas those with less egalitarian attitudes should favour a setting where women perform the lion's share of housework.

According to cognitive dissonance theory, individuals aim to organize their family life in accordance with their own attitudes (Festinger 1962), and Davis \& Greenstein (2009) conclude from their review that most studies indeed find that men's and women's gender role attitudes are in line with the proportion of housework they actually perform. For example, husbands and/or wives exhibiting egalitarian gender role attitudes were found to be more likely to share housework equally (Aassve et al. 2014). Moreover, longitudinal studies investigating changes in the division of housework after, for example, childbirth showed that egalitarian gender attitudes before motherhood reduced the shift towards a more traditional division of paid and domestic work after the transition to parenthood (e.g., Nitsche \& Grunow 2016; Schober 2013). Even in these longitudinal studies, however, endogeneity cannot be ruled out completely if prebirth gender role attitudes, childbirth, and adaptation of the sharing of housework are interrelated. In contrast to the first COVID-19 lockdown, parenthood is an event in anticipation of which couples will usually develop expectations about their subsequent division of labour (e.g., Dechant \& Rinklake 2016). The lockdown, however, hit individuals and couples unexpectedly, that is, without much time to develop new housework division arrangements consistent with their gender role attitudes. Hence, given the unforeseen nature of the COVID19 crisis and the concomitant changes within households, it offers a unique opportunity to study gender role attitudes' effect on changes in couples' division of domestic work.

Our first set of hypotheses derived from the above considerations refers to the expectation that gender role attitudes predict changes in housework from baseline to COVID-19; that is, we expect attitudes to moderate the effect of the COVID-19 pandemic on housework. At the individual level, men with egalitarian attitudes are expected to increase their housework more than men with traditional attitudes, whereas the opposite is expected for women. These changes 
in housework are expected to occur independent of the partner's gender role attitudes. At the couple level, we expect an interaction between the partners: If both partners express egalitarian attitudes, the division of housework will be more equal than in traditional couples or in those with divergent attitudes.

Our second set of hypotheses refers to changes over time during our observation period, that is, from the early phase of the first lockdown in April through its later phase in September. Specifically, we expect further adaptations in the division of housework depending on partners' gender role attitudes. In the unanticipated early phase of the lockdown, couples' reaction to the new situation might have been driven by gender role attitudes as well as by immediate and pragmatic decisions related to the partner's time availability and the additional demands of housework. During the summer, however, couples may have revised their initial 'pragmatic' arrangements to (re-)align with their pre-crisis gender role attitudes. Hence, we expect gender role attitudes to be a stronger predictor of couples' division of housework in September than in April.

\section{Data, variables and methods}

\subsection{Data and Sample}

Data. We analyse data from Understanding Society: The UK Household Longitudinal Study (Platt et al. 2020; also see Burton et al. 2020). Specifically, we use Wave 10 of the Understanding Society's main survey conducted in 2018-19 (University of Essex 2020) ${ }^{2}$ as well as four COVID-19 study waves conducted in April, May, June, and September 2020 (University of Essex 2021). The latter study was initiated as a high-frequency panel on people's experiences and reactions to the COVID-19 pandemic (Institute for Social and Economic Research 2021).

\footnotetext{
${ }^{2}$ For Wave 10, we built on the data preparation files provided by the Comparative Panel File project (see Turek et al. 2021).
} 
Eligible were all Understanding Society respondents who had participated in at least one of the previous two waves of the main survey. The first wave of the COVID-19 study was carried out in April 2020, with monthly waves until July and bi-monthly surveys from September 2020 onwards.

Survey timing in the pandemic context. Figure 1 puts the timing of the survey interviews into the context of the first pandemic wave. It plots the fieldwork periods of the survey waves against two proxies for pandemic activity and lockdown intensity, namely, the number of COVID-19 patients who were in hospitals and a measure of people's mobility patterns. Any effective lockdown measure will reduce people's mobility and increase their time spent at home. Therefore, we use aggregate information on the change in time spent in any residential area from the Google COVID-19 Community Mobility Reports as a proxy for the position on the lockdown-normality continuum (Google LLC 2020; Hudde \& Nitsche 2020). Both measures show that the country was most severely affected in early and mid-April, shortly before the interviews for the first COVID-19 survey wave were conducted. Towards the summer, hospitalizations neared zero, and the lockdown became moderately less intense. The fieldwork period for the September interviews roughly marks the end of the period with low hospitalizations and moderate-low lockdown intensity and the beginning of the second major infection wave. In summary, the April wave roughly captures the period of maximum pandemic impact; the May and June waves cover periods of relatively high but declining impact, and the September wave captures the temporary recovery to a relatively normal situation. 


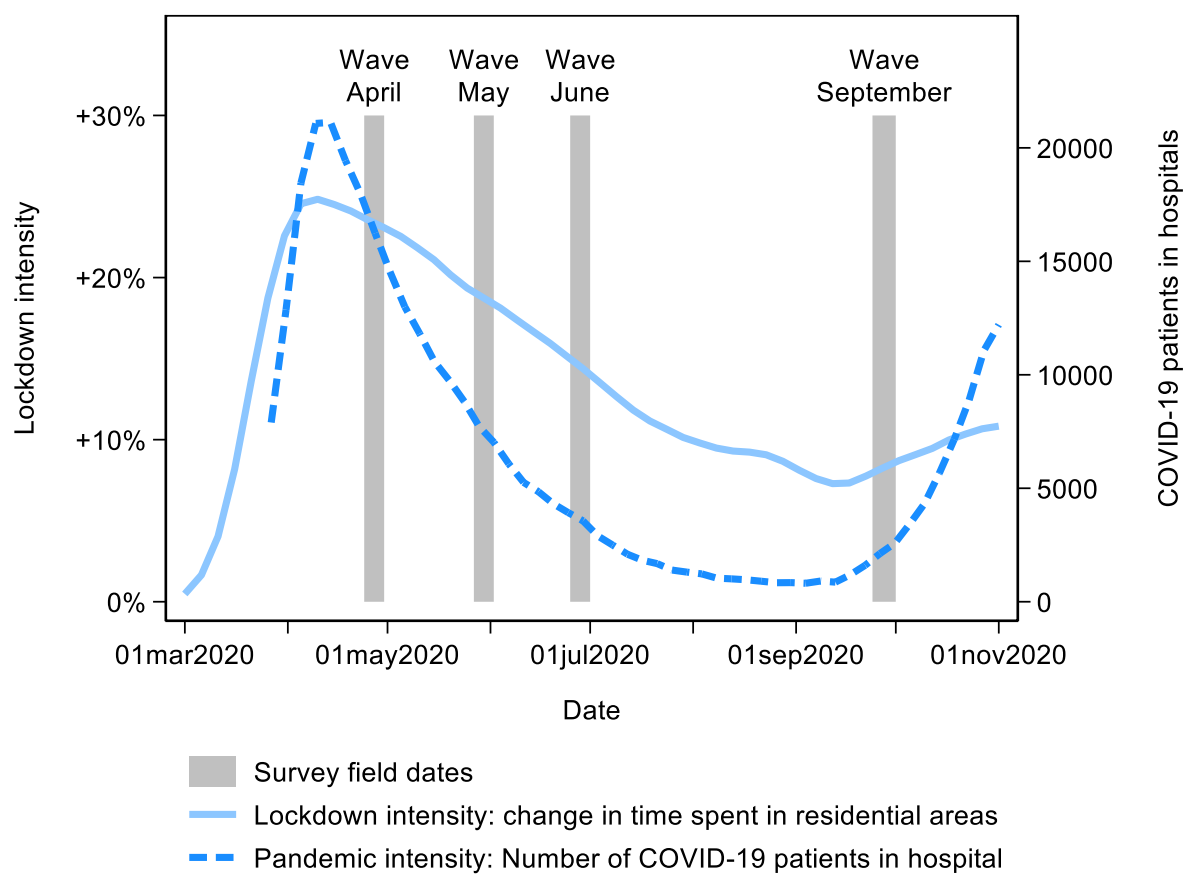

Fig 1: Timing of the COVID-19 survey periods in the context of pandemic impact. The proxy for lockdown intensity comes from the Google Covid-19 Community Mobility Reports and refers to the time spent in any residential area relative to a pre-pandemic baseline.

Survey methods and weights. Beginning in the Understanding Society study's Wave 8, face-to-face in-home interviewing was gradually replaced by web interviews (Burton et al. 2020). In Wave 10, 70\% of respondents were invited to participate via the web, and the other $30 \%$ were invited to participate face-to-face. These $30 \%$ consisted of a random sample $(20 \%$ of the total) and households that were predicted to have the lowest probability of participating online $(10 \%$ of the total). Telephone interviews were conducted with those who could not be reached via the web or in person. Among the completed interviews in Wave 10,59\% were realized via the web, $41 \%$ face-to-face, and less than $1 \%$ via telephone. For the COVID-19 study, the interview mode shifted almost entirely to online (Burton et al. 2020). Understanding Society has a complex design, and the data providers strongly suggest using weights (Institute for Social and Economic Research 2020). In the Understanding Society sample, some groups, such as people from Northern Ireland and ethnic minorities, are over-represented by design, and some groups are more likely to respond than others. Using weights assures that we average 
within-person changes over a representative population. We therefore apply the longitudinal weight provided for the most recently available wave to all analyses (Institute for Social and Economic Research 2021).

Sample selection. Our sample consists of opposite-sex couples where both partners participated in Wave 10 of the Understanding Society study and in at least one out of the four COVID-19 waves featuring the question on housework. Wave 10 ('baseline') includes 9,243 opposite-sex couples, corresponding to 18,486 individuals. Of these, 10,833 individuals participated in at least one of the COVID-19 waves (58.6\%); there were 4,097 couples where both partners participated (8,194 individuals). On average, these couples participated in 4.1 out of the five analysed waves.

There are relatively few missing values for our key variables: Missing information on attitudes occurred in $4.4 \%$ of couples, missing information on housework in $4.2 \%$, and missing work hours in $1.6 \%$. In total, the attrition due to missing data is $9.9 \%$ and therefore relatively low. Further, 31 couples were dropped because their Wave 10 interview was conducted after the onset of the COVID-19 pandemic, that is, in March or April 2020. After dropping those with a survey weight of zero (14.4\%), this leaves us with an analytical sample of 3,219 couples, observed for an average of 3.9 waves (12,702 couple-observations, 25,404 personobservations).

\subsection{Measures}

Partners' engagement in housework is measured as weekly hours spent on housework, such as “cooking, cleaning and doing the laundry". In the main study (Wave 10), respondents were asked "About how many hours do you spend on housework in an average week, such as time spent cooking, cleaning and doing the laundry?". In the COVID-19 study, housework engagement was covered in Waves 1, 2, 3, and 5, that is, in April, May, June, and September. In contrast to the main study, in the COVID-19 study, housework was measured with reference 
to the "last week" preceding the interview. The measure of the share of the couple's housework is calculated as own housework hours divided by the sum of one's own and one's partner's hours.

We use Understanding Society's Wave 10 for pre-COVID-19 information on gender role attitudes as a 'baseline' measure. For our analysis, accounting for pre-crisis attitudes is necessary to avoid endogeneity resulting from possible feedback of changes in couples' division of labour on partners' gender ideologies at the time of the COVID-19 interviews (Carlson \& Lynch 2013; also see Nitsche \& Grunow 2016). Our measure of gender role attitudes is derived from iterated principal factor analysis over four items that have also been used in previous studies on the division of housework (e.g., Fuwa 2004; Okun \& Raz-Yurovich 2019; Schober 2013; measured with 5-point scales ranging from "strongly agree" to "strongly disagree"), namely:

1. A husband's job is to earn money, a wife's job is to look after the home and family.

2. Both the husband and wife should contribute to the household income.

3. All in all, family life suffers when the woman has a full-time job.

4. A pre-school child is likely to suffer if his or her mother works.

All four items capture attitudes towards the gendered nexus between work and family/homemaking; that is, they all focus on a similar aspect or dimension of gender role attitudes (for discussions of different dimensions of gender role attitudes, see, for example, Grunow et al. 2018; Hudde, 2018). In particular, these items focus on women's roles as mothers, whether they should work for pay and whether working moms have a negative effect on family life. The first item explicitly mentions "to look after the home", i.e., to perform housework. A Cronbach's Alpha of 0.72 gives statistical support to the idea that these four items capture one latent, underlying factor. To isolate this factor, we used iterated principal factor analysis with promax rotation. The factor variable is coded such that higher values represent more egalitarian gender role attitudes. 
We control for changes in both partners' working hours because they affect partners' time availability and might thus confound the association between attitudes and the division of housework. Finally, we control for changes in the household composition, with two variables that each capture the number of children in the household aged zero to four, and aged five to eleven.

Table 1: Descriptive table: key variables.

\begin{tabular}{|c|c|c|c|c|c|c|c|}
\hline \multirow[t]{2}{*}{ Variables at the individual level } & \multicolumn{3}{|c|}{$\begin{array}{c}\text { Woman } \\
\left(n_{\text {ind. }}=3,219 ; n_{\text {obs. }}=12,702\right)\end{array}$} & \multicolumn{3}{|c|}{$\begin{array}{c}\text { Man } \\
\left(\mathrm{n}_{\text {ind. }}=3,219 ; \mathrm{n}_{\text {obs. }}=12,702\right)\end{array}$} & \multirow[b]{2}{*}{ range } \\
\hline & mean & sd & histogram & mean & sd & histogram & \\
\hline Hours of housework, baseline & 13.52 & 9.08 & $\mathbf{z}$ & 6.35 & 5.64 & & $0 ; 70$ \\
\hline Change in hours of housework & 1.32 & 8.12 & & 1.39 & 6.14 & & $-61 ; 70$ \\
\hline Gender role attitudes & 0.06 & 1.02 & & -.005 & 0.98 & & $-2.63 ; 1.91$ \\
\hline \multirow[t]{2}{*}{ Variables at the couple level } & $\left(\mathrm{n}_{\text {couples. }}\right.$ & $\begin{array}{l}\text { Coupl } \\
219 ; \mathrm{n}\end{array}$ & bs. $=12,702)$ & & & & \\
\hline & mean & sd & histogram & & & & range \\
\hline Men's \% of housework, baseline & 33.03 & 22.62 & & & & & $0 ; 100$ \\
\hline $\begin{array}{l}\text { Change in men's share of housework, in } \\
\text { \%-points }\end{array}$ & 2.06 & 18.10 & & & & & $-89 ; 100$ \\
\hline \multicolumn{8}{|l|}{ Attitude constellation, $\%$ of couples } \\
\hline - Both egalitarian & 32.32 & & & & & & \\
\hline - Woman less, man more egalitarian & 15.57 & & & & & & \\
\hline - Woman more, man less egalitarian & 19.39 & & & & & & \\
\hline - Both less egalitarian & 32.73 & & & & & & \\
\hline
\end{tabular}

\subsection{Methods}

For the descriptive analysis, we split the total sample by gender and gender role attitudes. For this purpose, we dichotomize our continuous measure of gender role attitudes, labelling attitudes below the gender-specific median as 'less egalitarian' and those above the median as 'more egalitarian'. We then compute and plot the average hours of housework and the men's average housework share by women's and men's attitudes. Confidence intervals are computed using pooled ordinary least squares regression with standard errors clustered at the individual/couple level. For the multivariate analysis and to study the effect of gender role attitudes on short-term changes in housework hours, we run linear panel regression models 
using fixed effects at the individual/couple level. This approach disregards differences in baseline levels between individuals/couples, but assesses changes in housework within individuals/couples over time (that is, each individual/couple is compared with itself at an earlier time as its control). Fixed-effects models thus eliminate all time-invariant factors by exploiting within-person/couple variability (that is, intra-individual changes over time) only, thereby avoiding that potentially unobserved time-invariant confounders bias our estimates (e.g., Brüderl \& Ludwig 2015).

Our hypotheses state that gender role attitudes predict how housework changes in response to the COVID-19 crisis; that is, attitudes moderate the effect of the pandemic on housework. To operationalize these hypotheses, the regression models include dummy variables for each monthly wave (that is, the average change in housework between the baseline and each COVID-19 wave) and the interaction terms between these dummy variables and the respondents' attitude (that is, the test of whether the degree of change is a function of respondents' pre-crisis attitude). The monthly dummies capture the degree to which the COVID-19 pandemic affected people's lives: The 'April' dummy, for example, captures the period of the pandemic with the most intense lockdown, whereas 'September' captures the recovery to a near-normal situation (see Figure 1).

\section{Results}

First, we look at partners' absolute hours of housework (Section 4.1) and then study the division of housework within couples (Section 4.2). From both angles, we examine our hypotheses that gender role attitudes predict the change in housework from baseline to COVID-19.

\subsection{Gender role attitudes and housework hours of men and women: the individual} perspective 
By comparing the housework hours of women and men (Figure 2; Panels A and B), we see that women, particularly those with less egalitarian attitudes, spent approximately twice as many hours on housework at any point in time. Men with less egalitarian attitudes engage least in domestic work. Hence, when looking at the overall level, we replicate the well-known associations among gender, gender role attitudes, and housework.

Figure 2 (Panels $C$ and $D$ ) also illustrates the change in housework hours for women and men during lockdown compared to the baseline measure. These results align with previous studies showing that men and women spent more hours doing housework during the crisis than in the pre-crisis period. This trend in housework roughly follows the course of the pandemic: housework is highest in April and May, when infection cases are also at their highest and the lockdown is at its most intense; in summer, when infection cases are low and the lockdown intensity is moderate, housework returns relatively close to baseline. 


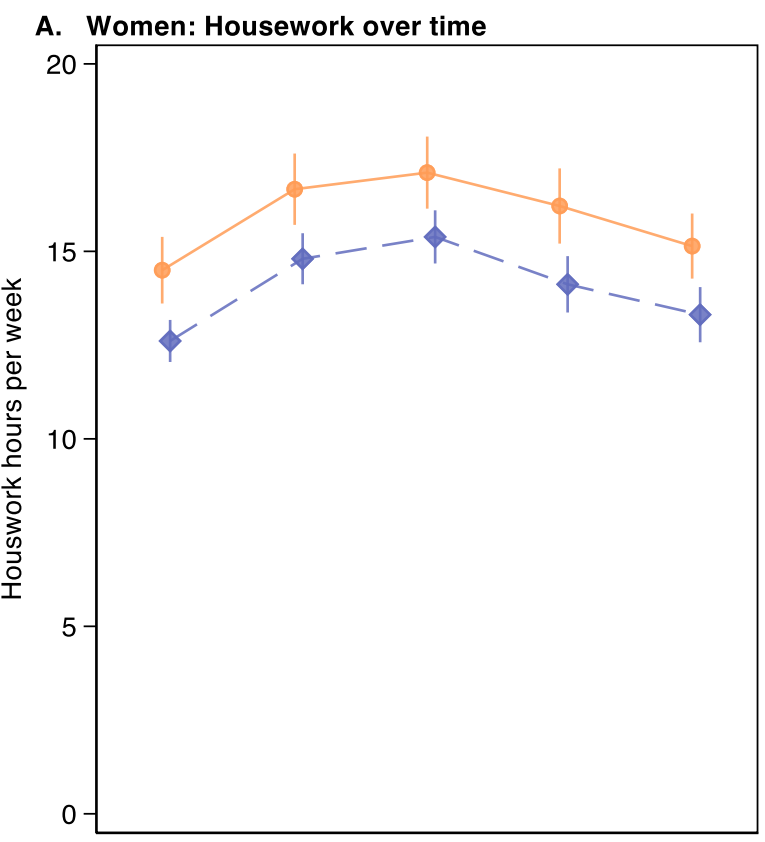

C. Women: Change in housework relative to basline

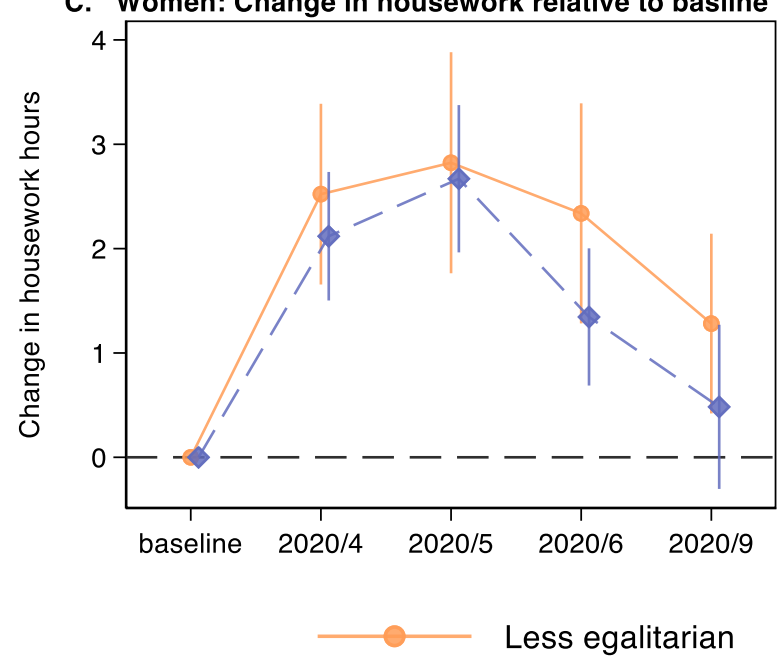

B. Men: Housework over time

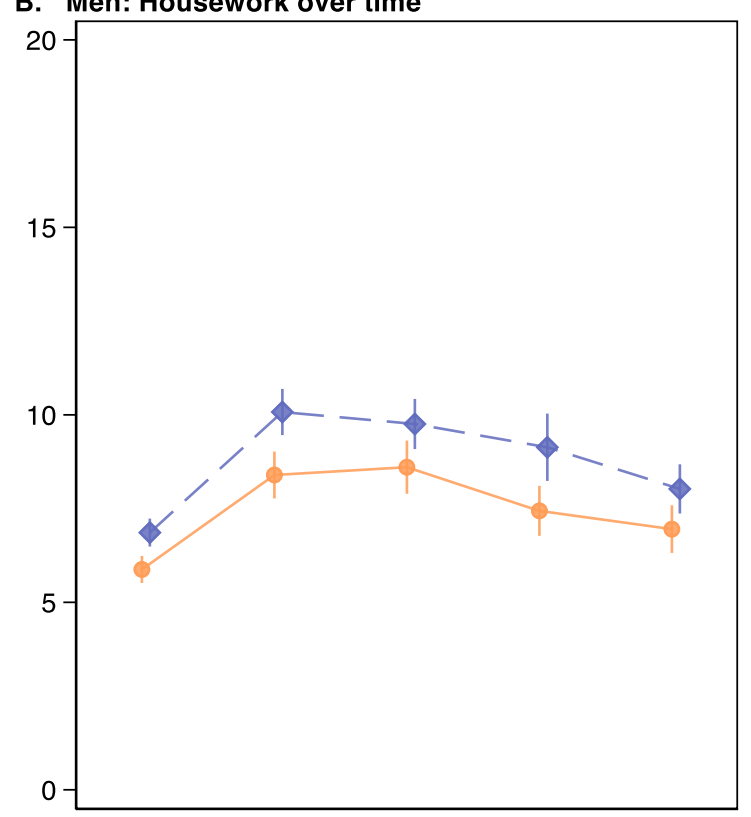

D. Men: Change in housework relative to basline

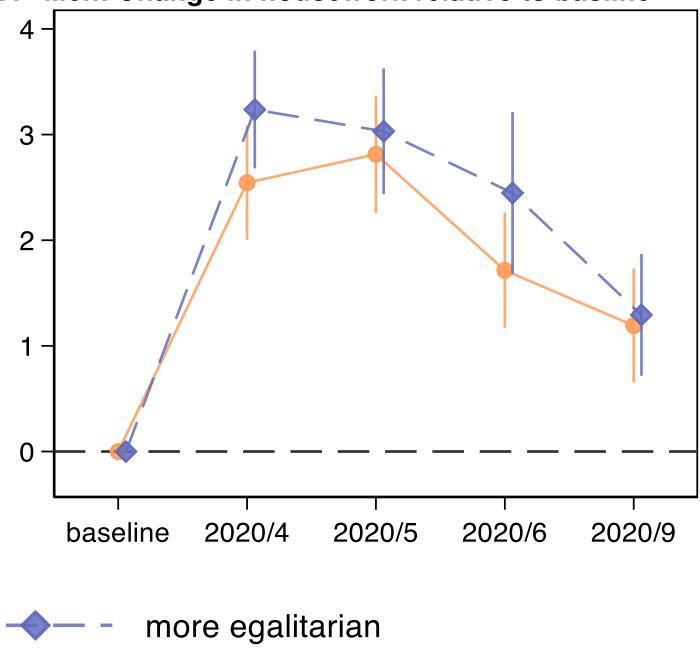

Fig 2: Descriptive findings on gender role attitudes and individuals' housework at the individual level (Women: $n_{\text {individuals }}=3,219 ; n_{\text {observations }}=12,702 ;$ men: $n_{\text {individuals }}=3,219 ;$ nobservations $\left.=12,702\right)$. Attitude groups are divided by the gender-specific median, i.e., "less egalitarian" refers to the less egalitarian half of the gender-specific sample. "Baseline" refers to Wave 10 of Understanding Society.

The pattern of change in housework from baseline to COVID-19 is similar between genders and attitude groups. Compared to the average number of hours they spent on housework before the COVID-19 crisis, women spent approximately two and a half more hours and men almost three more hours on housework in April/May. In September, women still spent approximately 50 minutes more on housework than at baseline, and men devoted 75 minutes more to housework. In contrast to our expectations, these changes in housework hours do not differ by individuals' pre-crisis gender role attitudes: Whereas the respective time spent on 
housework in groups with 'more'/'less' egalitarian attitudes differs at baseline, there is little difference in their response to the unforeseen COVID 19 crisis.

Figure 3 illustrates the effect of gender role attitudes on housework based on fixed-effects regression models controlling for one's own and one's partner's working hours (see Panels A and $B$; full results are presented in Table $A 1$ in the Appendix). None of the effects reach statistical significance. In tendency, however, women with more egalitarian attitudes reported smaller changes in housework hours, whereas men with more egalitarian attitudes increased their time spent on housework. The confidence intervals are not large, so the insignificance of the coefficients is unlikely to be due to our sample size or a lack of overall change in housework hours. What we observe instead is that, irrespective of their lack of statistical significance, the estimated 'effects' are substantively small (on the order of a 20-minute - or even smaller change in housework predicted by a one-standard-deviation change in gender role attitudes). Further, our expectation was that attitudes matter more in the latter than in the first months of the pandemic, but there is no evidence that attitudes matter at any point in time.

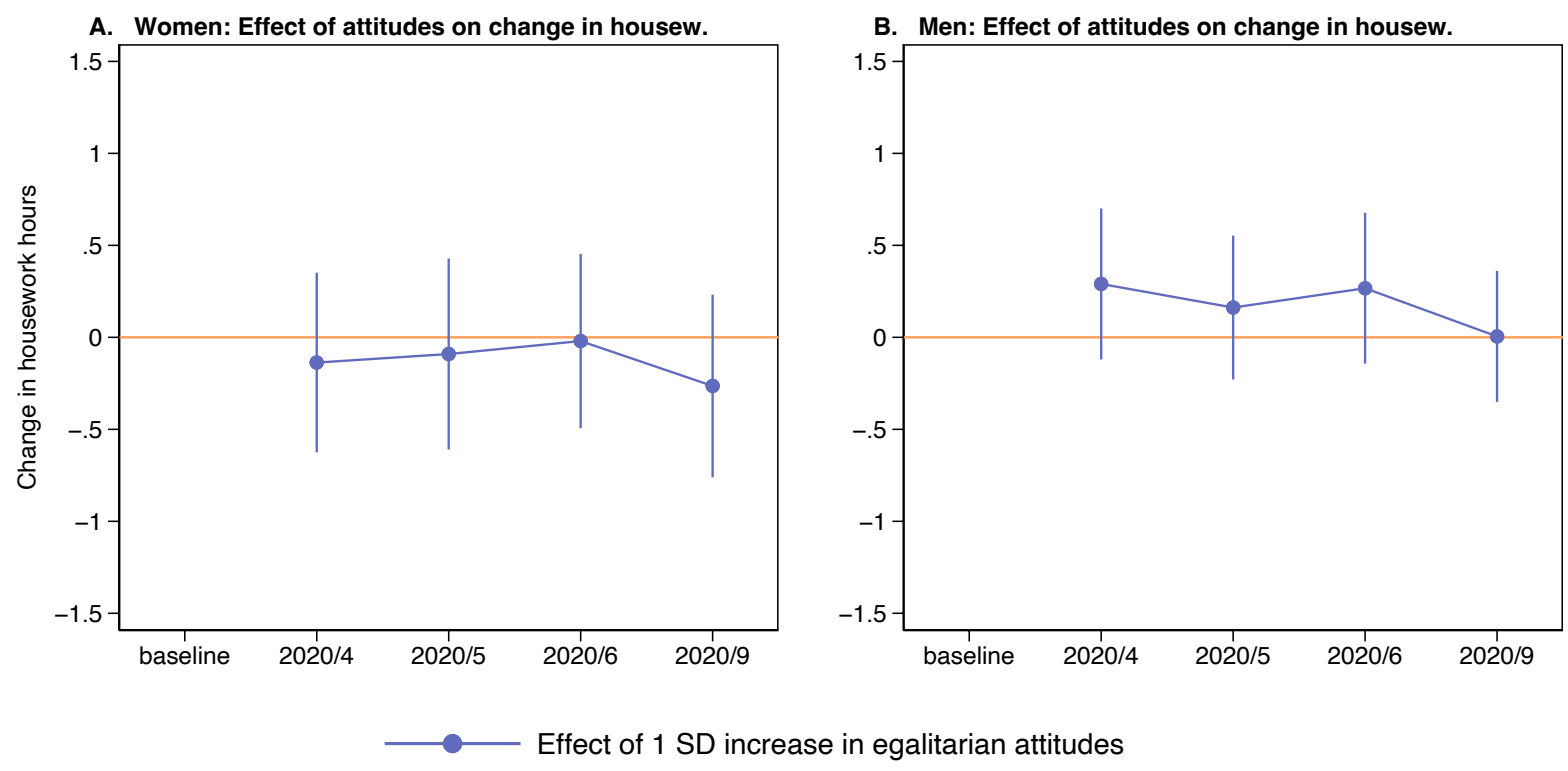

Fig 3: Effect of egalitarian attitudes on individuals' change in housework hours compared to baseline (results from fixed-effects regression models, see Table A1; Women: $n_{\text {individuals }}=3,219$; nobservations $_{1}$ 12,702; men: $n_{\text {individuals }}=3$, $\left.219 ; \mathrm{n}_{\text {observations }}=12,702\right)$. "Baseline" refers to Wave 10 of Understanding Society. 


\subsection{Gender role attitudes and partners' share in housework: the couple perspective}

In the previous section, we discussed individuals' absolute time spent doing housework. We now consider the couple's division of housework, that is, men's share of housework, by couples' gender role attitude constellations, namely, both partners express less egalitarian gender role attitudes ('traditional' couples), both partners hold more egalitarian attitudes ('egalitarian' couples), and two combinations of mixed gender role attitudes.

Figure 4 (Panel A) shows that at baseline, men's share of couples' housework is highest in egalitarian couples (38 percent) and lowest in traditional couples (28 percent). Moreover, men's attitudes seem to matter more than women's, as partners' shares of housework are more equally distributed in couples with egalitarian attitudes in men rather than women. Panel $B$ highlights the change in men's share of housework compared to the pre-crisis situation by the four different constellations of attitudes. In all couples, men's share increased significantly (by more than three percentage points on average) in the intense early lockdown phase. Hence, in relative terms, the pandemic increased gender equality in housework in all couple constellations. 


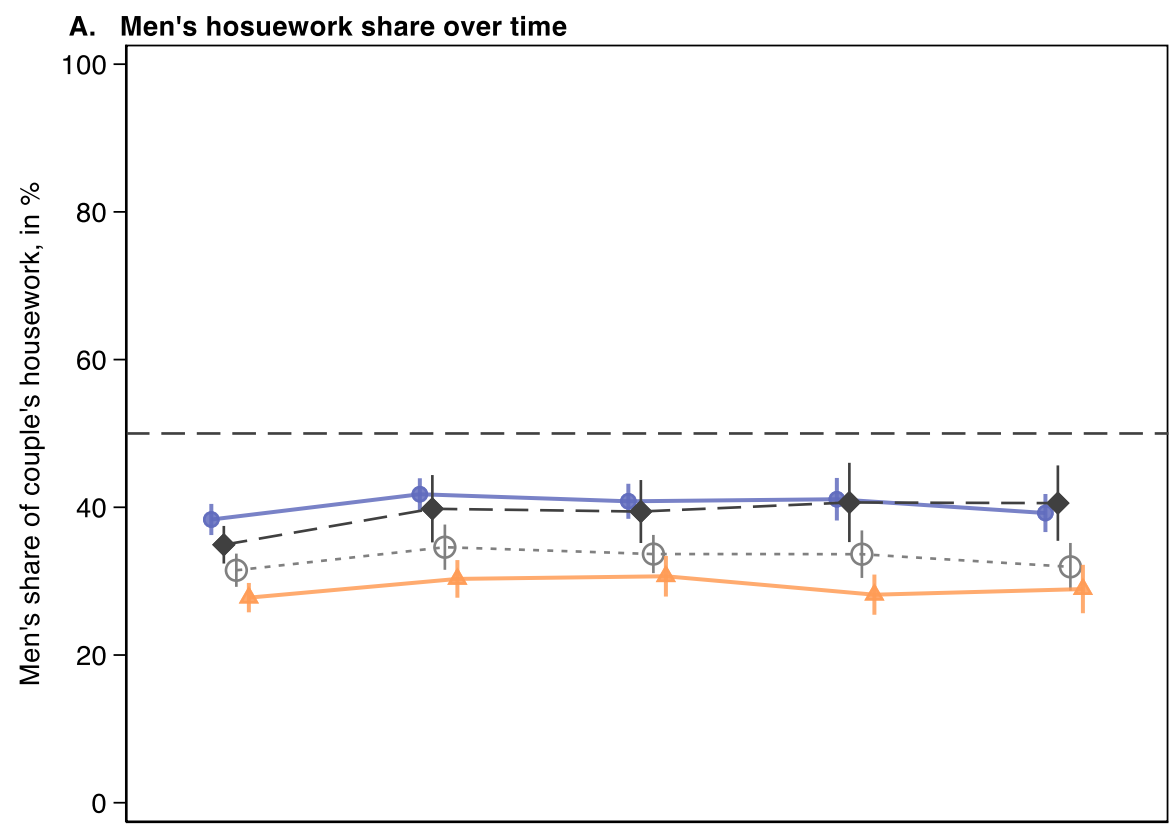

B. Change in men's housework share

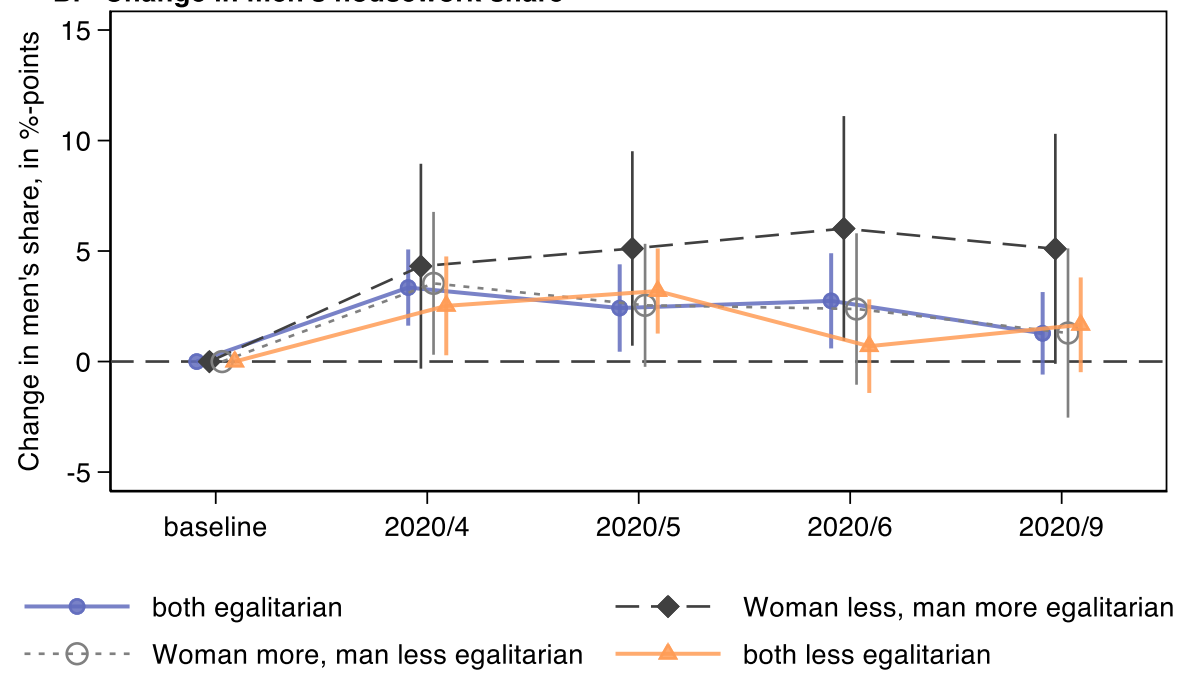

Fig 4: Descriptive findings on gender role attitudes and men's share of the couple's housework ( $\mathrm{n}_{\text {couples }}=3,219$; $\mathrm{n}_{\text {observations }}=12,702$ ). Attitude groups are divided by the gender-specific median, i.e., "woman less, man more egalitarian" refers to a couple where the woman comes from the less egalitarian half of women and the man from the more egalitarian half of men. "Baseline" refers to Wave 10 of Understanding Society.

On average, the pandemic had a positive effect on men's share of housework: At the peak of the first lockdown phase, men increased their share of housework by approximately three percentage points. By September, men's housework share decreased to a level slightly above the pre-crisis baseline. Concerning our research question, there is no clear association between attitude constellation and change in the division of housework. Our theoretical expectation was that men's share would increase most in couples where both are more egalitarian and least in couples where both are less egalitarian. However, this pattern does not materialize, and 
trajectories are almost identical in both types of homogamous couples and in couples where the woman is egalitarian and the man is not. The couples in which the man is egalitarian and the woman is not seems to deviate: in these couples, men's share remains substantially above baseline. However, the confidence interval is rather broad, so this finding should be interpreted with caution.

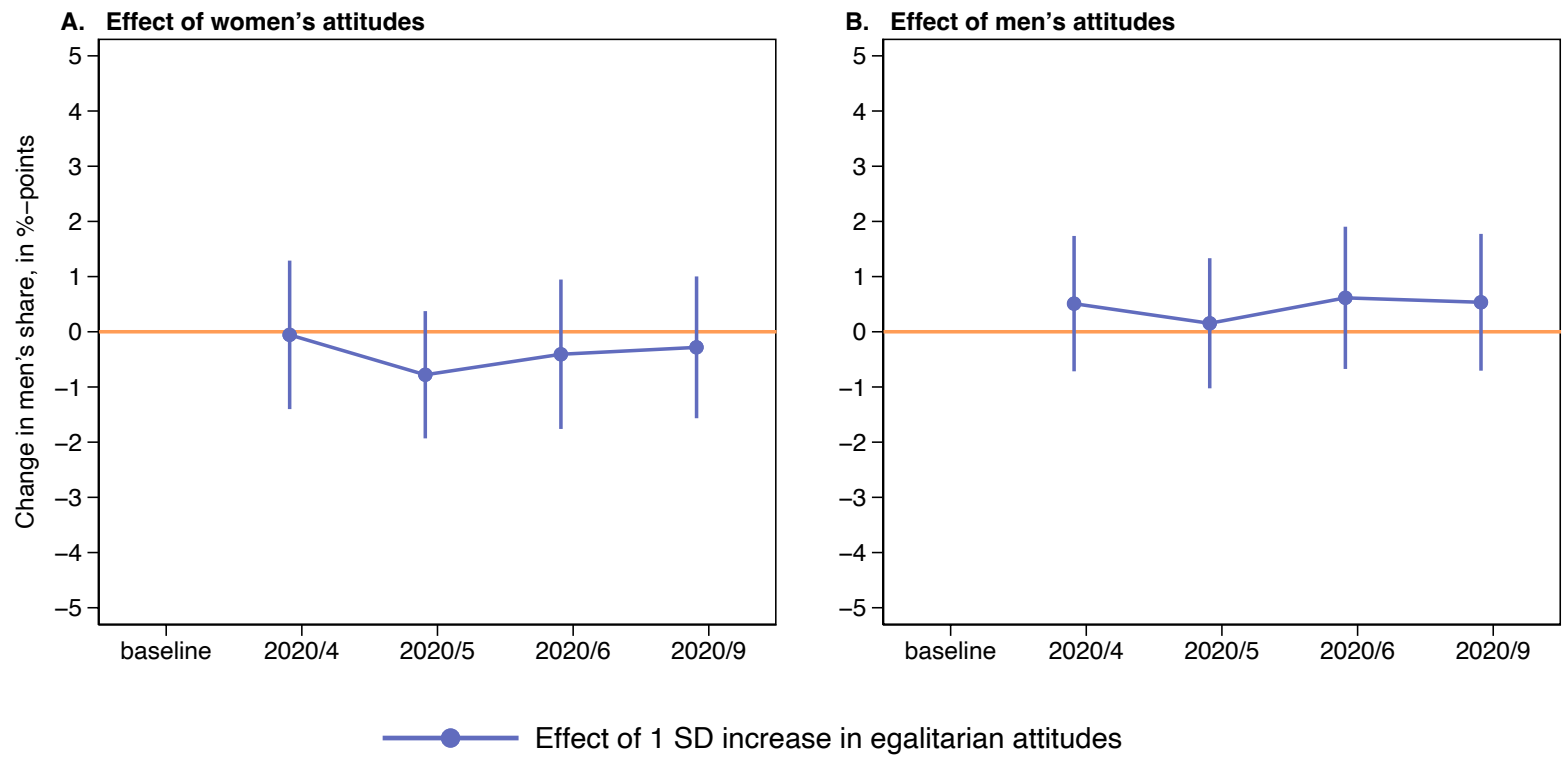

Fig 5: Effect of egalitarian attitudes on the change in men's share of the couple's housework compared to baseline (results from fixed-effects regression models, see Table A2; n couples $_{1}=3,219$; nobservations $_{1}$ 12,702). "Baseline" refers to Wave 10 of Understanding Society.

Figure 5 illustrates the effect of gender role attitudes on housework based on fixed-effects regression models controlling for both partners' working hours (full results are presented in Table A2 in the Appendix). The results show that there is no systematic effect of women's or men's attitudes at any month during the pandemic. The degree to which men change their share of the couples' housework in response to the crisis is therefore independent of women's attitudes (Panel A in Figure 5), men's attitudes (Panel B), or their interaction (Table A2 in the Appendix).

Similar as for individual housework, irrespective of their lack of statistical significance, the point estimates are small in substantive terms (less than a 1\%-point change in men's 
housework share predicted by a one-standard-deviation change in their gender role attitudes). That is, even if we cannot be certain whether there is a small effect or no effect, there is certainly no large effect of gender role attitudes on the hours spent on and share of housework during the COVID-19 crisis. In sum, we find no support for our first or second hypotheses.

\subsection{Robustness checks and further analyses}

To challenge these null findings, we conducted additional analyses. First, our main regression models included the attitudes as linear terms. This means that any non-linear relationship in the data might be overlooked. We therefore examined the associations using local linear smoothing, which allows for a flexible pattern of association (see Figures A1-A4 in the Appendix). This approach confirmed that there is no substantial association of any shape. Second, the dependent housework variables have a number of outliers, which might excessively impact the results. As a further test, we therefore recoded outliers. In these tests, the estimates remained almost identical (see Figures $A 5-A 6$ in the Appendix). Finally, COVID-19 might have changed people's income and thereby their bargaining position in the couples (Sullivan \& Gershuny 2016). The main models already control for working hours and changes therein. However, if people's risk of wage loss is systematically associated with gender role attitudes, and if this is not fully captured by changes in working hours, this might potentially distort the estimated effect of attitudes on housework. Therefore, we run models that add control variables for both partners' income. This does not change the estimated effect of gender role attitudes on housework (see Figure $A 7-A 8$ in the Appendix). In sum, the results of these further analyses underscore the conclusion that gender role attitudes do not predict how people's engagement in housework changed during the COVID-19 pandemic. 


\section{Summary and conclusions}

The present study set out to investigate the role of gender role attitudes in the dynamics of couples' division of housework in a very peculiar historical context: The COVID-19 lockdown of 2020. Data from the UK Household Longitudinal Study and four waves of its COVID-19 panel survey provided us with the opportunity to investigate couples' adaptation to changing circumstances following a truly exogenous shock, thereby avoiding issues of potential endogeneity common in related previous research. Our study thus contributes not only to the growing literature on gender inequalities during the pandemic (e.g., Alon et al. 2020; Oreffice \& Quintana-Domeque 2020) but also - and more generally - to a better understanding of how couples negotiate their division of labour (e.g., Geist \& Ruppaner 2018).

The main starting point for our research was observations indicating that changes in partners' relative resources and time availability cannot fully account for adaptations in the division of household labour following critical life events more generally, ranging from childbirth to retirement (e.g., Leopold \& Skopek 2018; Schober 2013a), and the 'COVID-19 shock' in particular (e.g., Andrew et al. 2020; Zamberlan et al. 2021). We therefore hypothesized, first, that pre-crisis gender role attitudes predict changes in housework from our pre-COVID-19 baseline observation to lockdown (that is, the period from April through September 2020). Second, we expected gender role attitudes to be stronger predictors of couples' division of housework in September than in April 2020, as couples may then have revised their pragmatic adaptations to the early and more intense lockdown in spring by arrangements more in line with their pre-crisis attitudes.

Neither of these hypotheses could be supported by the results of our empirical analyses: We found no evidence indicating that individuals' or couples' pre-crisis gender role attitudes affected changes in men's or women's absolute or relative contributions to housework at any time during lockdown. These null findings were confirmed by a series of robustness checks. However, both partners spent substantially more absolute time on housework throughout the 
COVID-19 crisis than before, especially in its early phase, and in relative terms, the pandemic seems to have contributed to an at least temporary, modest increase in gender equality in housework.

Against the background of fears of a 'patriarchal pandemic', this latter finding is good news. One should be careful, however, about drawing premature general conclusions regarding gender inequalities during the COVID-19 pandemic in the UK. One particular reason warranting such caution is the lacking consideration of another important component in couples' division of labour, childcare, which we were not able to assess in our analysis because its division between partners was not consistently measured in our data. Other UK studies suggest that mothers, on average, provided substantially more additional hours of childcare than fathers, but that there is also an important fraction of fathers who became substantially more involved in childcare during the COVID-19 crisis (e.g., Hupkau \& Petrolongo 2020; Sevilla \& Smith 2020; see Kreyenfeld \& Zinn 2021 for corresponding evidence from Germany). Overall, pre-crisis gender inequalities in couples' division of labour within the household do thus not seem to have undergone major changes - in the UK or elsewhere in Europe (e.g., Hank \& Steinbach 2021; Zamberlan et al. 2021). The survey question on housework in the data lists exemplary tasks, "cooking, cleaning and doing the laundry", which are typical female-typed tasks (Noonan 2001). Gender-neutral or male-typed tasks, such as household repairs and improvements or shopping are not listed. If a survey question also listed such tasks, this should increase the stated housework hours by men more than that of women, which would decrease the overall gender gap in housework hours. However, we are not aware of any argument suggesting that this would alter the effect of gender role attitudes on changes in housework hours during the pandemic.

An important question remains regarding why our expectation that gender role attitudes would matter for couples' adaptation to the novel situation during the initial COVID-19 lockdown was not confirmed by our empirical findings. Though we cannot provide a definitive 
answer, we propose two possible explanations. First, previous research claiming an impact of gender role attitudes on changes in the division of housework after major life course events may have suffered from potential endogeneity issues. Attitudes and behaviour are engaged in constant feedback: Attitudes influence behaviour, and behaviour influences attitudes. In fact, there may also be a feedback loop between attitudes and anticipated behaviour. For example, a woman planning to have a child may anticipate that motherhood will lead to reduced employment and increased housework, and she may adapt her attitudes to this anticipated change to avoid cognitive dissonance (Festinger 1962). The truly exogenous shock of the pandemic created a unique opportunity to rule out such potential issues of endogeneity. From this perspective, previous studies might have overestimated the actual role of gender ideologies.

Second, it could be that gender role attitudes matter under certain circumstances (e.g., Carriero \& Todesco 2018) but not under the specific circumstances of the unanticipated COVID-19 shock. There are at least two plausible relevant ways in which the COVID-19 shock may differ from life events, for which gender role attitudes matter. First, unlike these life events, the pandemic was unanticipated, with the consequence that people were not able to mentally prepare and develop a behavioural script that was in accordance with their attitudes. What speaks against this idea is that attitudes should be readily available and guide behaviour in a rapid and possibly subconscious way (Ajzen \& Fishbein 2005). If gender role attitudes have little impact on behaviour under unanticipated circumstances, this would weaken their relevance for family functioning, given that unexpected shocks are not rare - think, for example, of health crises in the family or unexpected job changes, such as a sudden increase or decrease in working hours. A second relevant way in which the pandemic differs from other changes in life circumstances is that COVID-19 is a temporary shock, one that changes couples' lives for a few months before things return to normal (or at least, this is what most people expected to happen during the first pandemic wave in 2020). People might have expected that any change in housework and the gender balance would eventually return to the pre-crisis level. In practice, 
this means that, for example, a man with traditional gender role attitudes might be willing to increase his engagement during the pandemic because he is confident that the pandemic will have no long-lasting effect and he will be able to return to his practice of doing only a few hours of housework once the pandemic is over.

Whether or not gender ideologies translate into behaviours (and changes therein) appears to vary across situational contexts (see Carriero \& Todesco 2018 for a related discussion). Despite its null findings, our study offers several promising avenues for future research. It will be important to investigate, for example, whether or how individuals' gender role attitudes change in the further course and aftermath of the COVID-19 crisis (e.g., Reichelt et al. 2021), as has been previously observed after other critical life events (such as the transition to parenthood; Schober \& Scott 2012). In particular, a distinction between anticipated and unforeseen life events accompanied by short-term and long-term adaptions of behaviour might be a promising avenue for examining the relevance of gender role attitudes to couples' behaviours and attitude-behaviour feedback loops. Moreover, even though gender role attitudes did not predict how couples adapted their division of household labour during lockdown, they might well be relevant to couples' adaptation to the COVID-19 crisis in other important domains, such as fertility (e.g., Okun \& Raz-Yurovich 2019; Voicu \& Bădoi 2021). 


\section{References}

Aassve, A., Fuochi, G., \& Mencarini, L. (2014). Desperate Housework: Relative Resources, Time Availability, Economic Dependency, and Gender Ideology Across Europe. Journal of Family Issues, 35(8), 1000-1022.

Ajzen, I., \& Fishbein, M. (2005). The Influence of Attitudes on Behavior. In D. Albarracín, B. T. Johnson, \& M. P. Zanna (Eds.), The Handbook of Attitudes (p. 173-221). Lawrence Erlbaum Associates Publishers.

Alon, T., Doepke, M., Olmstead-Rumsey, J. \& Tertilt, M. (2020). The impact of COVID-19 on gender equality. NBER Working Paper \# 26947, Cambridge.

Andrew, A., Cattan, S., Costa Dias, M., ..., \& Sevilla, A. (2020). The gendered division of paid and domestic work under lockdown. IZA Discussion Paper No. 13500, Bonn.

Baxter, J., Hewitt, B. \& Haynes, M. (2008). Life course transitions and housework: Marriage, parenthood, and time on housework. Journal of Marriage and Family, 70, 259-272. doi:10.1111/j.1741-3737.2008.00479.x

Benzeval, M., Borkowska, M., Burton, J., ..., \& Read, B. (2020) Understanding Society COVID-19 Survey April Briefing Note: Home schooling. Understanding Society Working Paper No 12/2020, ISER, University of Essex.

Brüderl, J., \& Ludwig, V. (2015). Fixed-effects panel regression. In H. Best \& C. Wolf (Eds.), The SAGE Handbook of Regression Analysis and Causal Inference (pp. 327-357). London: Sage. doi:10.4135/9781446288146.n15

Burton, J., Lynn, P. \& Benzeval, M. (2020). How Understanding Society: The UK Household Longitudinal Study adopted to the COVID-19 pandemic. Survey Research Methods, 14, 235-239. doi:10.18148/srm/2020-v14i2.7746

Carlson, D.L. \& Lynch, J.L. (2013). Housework: Cause and consequence of gender ideology? Social Science Research, 42, 1505-1518. doi:10.1016/j.ssresearch.2013.07.003 
Carriero, R., \& Todesco, L. (2018). Housework division and gender ideology: When do attitudes really matter? Demographic Research, 39, 1039-1064. doi:10.4054/DemRes.2018.39.39

Chemaly, S. (2020). Coronavirus could hurt women the most. Here's how to prevent a patriarchal pandemic. https://www.nbcnews.com/think/opinion/coronavirus-could-hurtwomen-most-here-s-how-prevent-patriarchal-ncna1186581 [accessed: February 07, 2021].

Knize, V., Tobler, L., Christoph, B., Fervers, L. \& Jacob, M. (2021) Workin' moms ain’t doing so bad: Evidence on the gender gap in working hours at the outset of the COVID-19 pandemic. Journal of Family Research. doi:https://doi.org/10.20377/jfr-714

Craig, L., Perales, F., Vidal, S. \& Baxter, J. (2016). Domestic outsourcing, housework time, and subjective time pressure: New insights from longitudinal data. Journal of Marriage and Family, 78, 1224-1236. doi:10.1111/jomf.12321

Crompton, R., Brockmann, M. \& Lynoette, C. (2005). Attitudes, women's employment and the domestic division of labour: A cross-national analysis in two waves. Work, Employment and Society, 19, 213-233. doi:10.1177/09500170017005053168

Davis, S.N. \& Greenstein, T.N. (2009). Gender ideology: Components, predictors, and consequences. Annual Review of Sociology, 35, 87-105. doi:10.1146/annurev-soc070308-115920

Dechant, A. \& Rinklake, A. (2016). Anticipating motherhood and fatherhood: German couples' plans for childcare and paid work. In D. Grunow \& M. Evertsson (eds.), Couples' Transitions to Parenthood. Analysing Gender and Work in Europe (pp. 103-124), Cheltenham: Edward Elgar. doi:10.4337/97811785366000.00015.

Del Boca, D., Oggero, N., Profeta, P. \& Rossi, M.C. (2020). Women's work, housework and childcare, before and during COVID-19. Review of Economics of the Household, 18, 1001-1017. doi:10.1007/s11150-020-09502-1 
Fauser, S. (2019). Time availability and housework: The effect of unemployment on couples' hours of household labor. Social Science Research, 83, 102304. doi:10.1016/j.ssresearch.2019.04.017

Felstead, A. \& Reuschke, D. (2020). Homeworking in the UK: Before and during the 2020 lockdown. WISERD Report, Cardiff.

Festinger, L. (1962). A Theory of Cognitive Dissonance (Vol. 2). Stanford University Press.

Fodor, É., Gregor, A., Koltai, J. \& Kováts, E. (2021). The impact of COVID-19 on the gender division of childcare work in Hungary. European Societies, 23, S95-S110. doi:10.1080/14616696.2020.1817522

Fuwa, M. (2004). Macro-level gender inequality and the division of household labor in 22 countries. American Sociological Review, 69, 751-767. doi: 10.1177/ 000312240406900601

Geist, C. \& Ruppaner, L. (2018). Mission impossible: New housework theories for changing families. Journal of Family Theory \& Review, 10, 242-262. doi:10.1111/jftr.12245

Gershuny, J., Bittman, M. \& Brice, J. (2005). Exit, voice, and suffering: Do couples adapt to changing employment patterns? Journal of Marriage and Family, 67, 656-665. doi:10.1111/j.1741-3737.2005.00160.x

Google LLC (2021) Google COVID-19 Community Mobility Reports. Retrieved from: https://www.google.com/covid19/mobility/ [accessed: 26 February 2021].

Grunow, D., Begall, K. and Buchler, S. (2018). Gender ideologies in Europe: A multidimensional framework, Journal of Marriage and Family, 80(1), pp. 42-60. doi: 10.1111/jomf.12453.

Hank, K. \& Steinbach, A. (2021). The virus changed everything, didn't it? Couples' division of housework and childcare before and during the Corona crisis. Journal of Family Research, 33, 99-114. doi:10.20377/jfr-488 
Hipp, L. \& Bünning, M. (2021). Parenthood as a driver of increased gender inequality during COVID-19? Exploratory evidence from Germany. European Societies, 23, S658-S673. doi:10.1080/14616696.2020.1833229

Horne, R. M., Johnson, M. D., Galambos, N. L., \& Krahn, H. J. (2018). Time, money, or gender? Predictors of the division of household labour across life stages. Sex Roles, 78, 731-743. doi:10.1007/s11199-017-0832-1

Hudde, A. (2018). Societal agreement on gender role attitudes and childlessness in 38 countries, European Journal of Population, 34(5), pp. 745-767. doi: 10.1007/s10680-017-9459-8.

Hudde, A. \& Engelhardt, H. (2020). Intra-couple (dis)similarity in gender role attitudes and the transition to parenthood in Germany. European Sociological Review, 36, 852-867. doi:10.1093/esr/jcaa024

Hudde, A., \& Nitsche, N. (2020). Countries Embracing Maternal Employment Have Opened Schools Sooner after COVID-19 Lockdowns. SocArXiv, 11 Sept. 2020. doi:10.31235/osf.io/k7qe9

Hupkau, C. \& Petrolongo, B. (2020). Work, care and gender during the COVID-19 crisis. Fiscal Studies, 41, 623-651. doi:10.1111/1475-5890.12245

Institute for Social and Economic Research (2021). Understanding Society COVID-19 User Guide. Version 6.0, January 2021. Colchester: University of Essex.

Kalmijn, M. (2005). Attitude alignment in marriage and cohabitation: The case of sex-role attitudes. Personal Relationships, 12, 521-535. doi:10.1111/j.1475-6811-2005.00129.x

Kreyenfeld, M. \& Zinn, S. (2021). Coronavirus and care: How the coronavirus crisis affected fathers“ involvement in Germany. Demographic Research, 44, 99-124. doi:10.4054/DemRes.2021.44.4

Kühhirt, M. (2012). Childbirth and the long-term division of labour within couples: How do substitution, bargaining power, and norms affect parents' time allocation in West Germany? European Sociological Review, 28, 565-582. doi:10.1093/esr/jcr026 
Lachance-Grzela, M., \& Bouchard, G. (2010). Why do women do the lion's share of housework? A decade of research. Sex Roles, 63, 767-780. doi:10.1007/s11199-010$9797-z$

Leopold, T. \& Skopek, J. (2018). Retirement and changes in housework: A panel study of dual earner couples. Journals of Gerontology: Social Sciences, 73, 733-743. doi:10.1093/geronb/gbw121

Leopold, T., Skopek, J. \& Schulz, F. (2018). Gender convergence in housework time: A life course and cohort perspective. Sociological Science, 5, 281-303. doi:10.15195/v5.a13

McHugh, M.C. \& Frieze, I.H. (1997). The measurement of gender-role attitudes: A review and commentary. Psychology of Women Quarterly, 21, 1-16. doi:10.1111/j.14716402.1997.tb00097.x

McMunn, A., Bird, L., Webb, E. \& Sacker, A. (2020). Gender divisions of paid and unpaid work in contemporary UK couples. Work, Employment and Society, 34, 155-173. doi:10.1177/0950017019862153

Nitsche, N. \& Grunow, D. (2016). Housework over the course of relationships: Gender ideology, resources, and the division of housework from a growth curve perspective. Advances in Life Course Research, 29, 80-94. doi:10.1016/j.alcr.2016.02.001

Noonan, M. C. (2001). The Impact of Domestic Work on Men's and Women's Wages. Journal of Marriage and Family, 63(4), 1134-1145. doi:10.1111/j.1741-3737.2001.01134.x

Okun, B.S. \& Raz-Yurovich, L. (2019). Housework, gender role attitudes, and couples ‘ fertility intentions: Reconsidering men's roles in gender theories of family change. Population and Development Review, 45, 169-196. doi:10.1111/padr.12207

Oreffice, S. \& Quintana-Domeque, C. (2020). Gender inequality in COVID-19 times: Evidence from UK Prolific participants. IZA Discussion Paper No. 13463, Bonn. 
Pailhé, A., Solaz, A. \& Souletie, A. (2019). How do women and men use extra time? Housework and childcare after the French 35-hour workweek regulation. European Sociological Review, 35, 807-824. doi:10.1093/esr/jcz039

Pailhé, A., Solaz, A. \& Stanfors, M. (2021). The great convergence: Gender and unpaid work in Europe and the United States. Population and Development Review, 47 (1), 181-217. doi:10.1111/padr.12385

Platt, L., Knies, G., Luthra, R., Nandi, A. \& Benzeval, M. (2020) Understanding Society at 10 years. European Sociological Review, 36, 976-988. doi:10.1093/esr/jcaa031.

Raz-Yurovich, L. \& Marx, I. (2019). Outsourcing housework and highly skilled women's labour force participation - An analysis of a policy intervention. European Sociological Review, 35, 205-224. doi:10.1093/esr/jcz001

Reichelt, M., Makovi, K. \& Sargsyan, A. (2021). The impact of COVID-19 on gender inequality in the labor market and gender-role attitudes. European Societies, 23, S228S245. doi:10.1080/1466696.2020.1823010

Schober, P.S. (2013a). The parenthood effect on gender inequality: Explaining the change in paid and domestic work when British couples become parents. European Sociological Review, 29, 74-85. doi:10.1093/esr/jcr041

Schober, P.S. (2013b). Maternal labor market return and domestic work after childbirth in Britain and Germany. Community, Work \& Family, 16, 307-326. doi:10.1080/13668803.2013.820096

Schober, P.S. (2013c). Gender equality and outsourcing of domestic work, childbearing, and relationship stability among British couples. Journal of Family Issues, 34(1), 25-52.

Schober, P.S. \& Scott, J. (2012). Maternal employment and gender role attitudes: Dissonance among British men and women in the transition to parenthood. Work, Employment and Society, 26, 514-530. doi:10.1177/0950017017012438577 
Sevilla, A. \& Smith, S. (2020). Baby steps: The gender division of childcare during the COVID19 pandemic. Oxford Review of Economic Policy, 36, S169-S186. doi:10.1093/oxrep/graa027

Stenpaß, A. \& Kley, S. (2020). It's getting late today, please do the laundry - The influence of long-distance commuting on the division of domestic labor. Journal of Family Research, 22, 274-306. doi:10.20377/jfr-358

Sullivan, O. (2013). What do we learn about gender by analyzing housework separately from child care? Some considerations from time-use evidence. Journal of Family Theory \& Review, 5, 72-84. doi:10.1111/jftr.12007

Sullivan, O., \& Gershuny, J. (2016). Change in Spousal Human Capital and Housework: A Longitudinal Analysis. European Sociological Review, 32(6), 864-880. doi: 10.1093/esr/jcw043

Szinovacz, M.E. (2000). Changes in housework after retirement: A panel analysis. Journal of Marriage and Family, 62, 78-92. doi:10.1111/j.1741-3737.2000.00078.x

Turek, K., Kalmijn, M. \& Leopold, T. (2021). The Comparative Panel File: Harmonized Household Panel Surveys from Seven Countries. European Sociological Review, 37, 505523. doi:10.1093/esr/jcab006

University of Essex, Institute for Social and Economic Research, NatCen Social Research \& Kantar Public. (2020). Understanding Society: Waves 1-10, 2009-2019 and Harmonised BHPS: Waves 1-18, 1991-2009. [data collection]. 13th Edition. UK Data Service. SN: 6614. doi:10.5255/UKDA-SN-6614-14.

University of Essex, Institute for Social and Economic Research. (2021). Understanding Society: COVID-19 Study, 2020. [data collection]. 7th Edition. UK Data Service. SN: 8644. doi:10.5255/UKDA-SN-8644-7 
Uunk, W. \& Lersch, P.M. (2019). The effect of regional gender-role attitudes on female labour supply: A longitudinal test using the BHPS, 1991-2007. European Sociological Review, 36, 669-683. doi:10.1093/esr/jcz026

van der Lippe, T., Treas, J. \& Norbutas, L. (2018). Unemployment and the division of housework in Europe. Work, Employment and Society, 32, 650-669. doi:10.1177/0950017017690495

Voicu, M. \& Badoi, D. (2021). Fertility and the COVID-19 crisis: Do gender roles really matter? European Societies, 23, S887-S904. doi:10.1080/14616696.2020.1822537

Xue, B. \& McMunn, A. (2020). Gender differences in the impact of the Covid-19 lockdown on unpaid care work and psychological distress in the UK. SocArXiv, August 21. doi:10.31235/osf.io/wzu4t.

Zamberlan, A., Gioachin, F. \& Gritti, D. (2021). Work less, help out more? The persistence of gender inequality in housework and childcare during UK COVID-19. Research in Social Stratification and Mobility, 73, 100583. doi:10.1016/j.rssm.2021.100583

Zoch, G., Bächmann, A.-C. \& Vicari, B. (2021). Who cares when care closes? Carearrangements and parental working conditions during the COVID-19 pandemic in Germany. European Societies, 23, S576-S588. doi:10.1080/14616696.2020.1832700 


\section{Appendix}

Table A1: Individual level: change in women's and men's weekly hours of housework. Fixedeffects regression models. Figure 3 in the main paper is based on these regression models.

Women's housework hours

Men's hours

\section{Dummies for COVID-19 waves}

(reference category: baseline)

$2020 / 4$

$1.78^{* * *} \quad[1.20,2.37] \quad 2.51^{* * *}$

$[2.11,2.90]$

$2020 / 5$

$2.35^{* * *}$

$[1.71,2.99]$

$2.46^{* * *}$

[2.06,2.86]

2020/6

$1.43^{* * *}$

$[0.82,2.03]$

$1.79^{* * *}$

2020/9

$0.73^{* *}$

$[0.17,1.28]$

$1.16^{* * *}$

$[1.37,2.21]$

Interaction: Dummies for COVID-

19 waves $X$ Women's attitudes

2020/4 \# Women's attitudes

$-0.14 \quad[-0.63,0.35]$

2020/5 \# Women's attitudes

$-0.09 \quad[-0.61,0.43]$

2020/6 \# Women's attitudes

$-0.02 \quad[-0.49,0.45]$

2020/9 \# Women's attitudes

$-0.26 \quad[-0.76,0.23]$

Interaction: Dummies for COVID-

19 waves $X$ Men's attitudes

2020/4 \# Men's attitudes

$0.29 \quad[-0.12,0.70]$

2020/5 \# Men's attitudes

$0.16 \quad[-0.23,0.55]$

2020/6 \# Men's attitudes

$0.27 \quad[-0.14,0.68]$

2020/9 \# Men's attitudes

$0.01 \quad[-0.35,0.36]$

\section{Control variables}

Women's work hours

Men's work hours

$-0.06^{* * *} \quad[-0.09,-0.04] \quad 0.04^{* * *} \quad[0.02,0.06]$

No. kids aged 0-4 in hh

$-0.00 \quad[-0.02,0.02] \quad-0.06^{* * *}$

$[-0.08,-0.04]$

No. kids aged 5-11 in hh

$1.85^{*}$

$[0.25,3.45]$

$0.94^{+}$

$[-0.00,1.88]$

Constant

$2.13^{* * *}$

$[1.12,3.13]$

$1.10^{* *}$

$[0.27,1.94]$

\begin{tabular}{|c|c|c|c|}
\hline Constant & 0.03 & 0.30 & {$[-0.40,1.00]$} \\
\hline $\mathrm{n}_{\text {observations }}$ & 12702 & 12702 & \\
\hline $\mathrm{n}_{\text {individuals }}$ & 3219 & 3219 & \\
\hline
\end{tabular}

95\% confidence intervals in brackets

${ }^{+} p<0.10,{ }^{*} p<0.05,{ }^{* *} p<0.01,{ }^{* * *} p<0.001$ 
Table A2: Couple level: change in women's and men's weekly hours of housework. Fixedeffects regression models. Figure 5 is based on these models.

(1)

Men's share
(2)

Men's share
(3)

Men's share

\section{Dummies for COVID-19 waves}

(reference category: baseline)

$2020 / 4$

$2020 / 5$

$2020 / 6$

$2020 / 9$

\section{Interaction: Dummies for COVID-}

19 waves $X$ Women's attitudes

2020/4 \# Women's attitudes

2020/5 \# Women's attitudes

2020/6 \# Women's attitudes

2020/9 \# Women's attitudes

\section{Interaction: Dummies for COVID-}

\section{9 waves $X$ Men's attitudes}

2020/4 \# Men's attitudes

2020/5 \# Men's attitudes

2020/6 \# Men's attitudes

2020/9 \# Men's attitudes

Interaction: Dummies for COVID-

19 waves $X$ Women's attitudes $X$

\section{Men's attitudes}

2020/4 \# Women's attitudes \# Men's attitudes

2020/5 \# Women's attitudes \# Men's attitudes

2020/6 \# Women's attitudes \# Men's attitudes

2020/9 \# Women's attitudes \# Men's

attitudes

\section{Control variables}

Women's work hours

Men's work hours

No. kids aged $0-4$ in hh

0.51

$[-0.72,1.74]$

0.15

$[-1.02,1.33]$

0.62

$[-0.67,1.90]$

0.53

$[-0.70,1.77]$

$0.19^{* * *}$

$[0.12,0.25]$

$-0.14^{* * *}$

$[-0.20,-0.08]$

$0.95 \quad[-1.56,3.46]$

$\begin{array}{lll}3.17^{* * *} & {[1.79,4.56]} & 3.24^{* * *} \\ 2.94^{* * *} & {[1.69,4.20]} & 3.14^{* * *} \\ 2.63^{* * *} & {[1.20,4.06]} & 2.77^{* * *} \\ 2.02^{* *} & {[0.62,3.42]} & 2.24^{* *}\end{array}$

$[1.54,4.94]$

[1.67,4.60]

[1.12,4.41]

$[0.58,3.91]$

$\begin{array}{llll}-0.06 & {[-1.40,1.29]} & -0.29 & {[-2.01,1.43]} \\ -0.78 & {[-1.93,0.37]} & -1.00 & {[-2.44,0.44]} \\ -0.41 & {[-1.76,0.95]} & -0.78 & {[-2.41,0.86]} \\ -0.28 & {[-1.57,1.00]} & -0.61 & {[-2.24,1.01]}\end{array}$

0.62

$[-1.01,2.26]$

0.59

$[-0.90,2.07]$

0.95

$[-0.64,2.54]$

0.78

$[-0.82,2.39]$

$-0.04$

$[-1.34,1.26]$

$-0.33$

$[-1.45,0.78]$

$-0.14$

$[-1.43,1.14]$

$-0.35$

$[-1.57,0.86]$

No. kids aged 5-11 in hh

$0.19^{* * *}$

$[0.12,0.25]$

$0.19^{* * *}$

$[0.12,0.25]$

$-0.14^{* * *}$

$[-0.20,-0.08]$

$-0.14^{* * *}$

$[-0.19,-0.08]$

0.88

$[-1.64,3.39]$

0.95

$[-1.57,3.48]$

$-1.29 \quad[-3.43,0.84]$

$-1.30$

$[-3.44,0.84]$

$-1.29$

$[-3.43,0.85]$

Constant

$33.60^{* * *}$

[31.26,35.95]

$[31.27,35.94]$

[31.23,35.90]

$\mathrm{n}_{\text {observations }}$

12702

12702

12702

$\mathrm{n}_{\text {couples }}$

3219

3219

3219

$95 \%$ confidence intervals in brackets

${ }^{+} p<0.10,{ }^{*} p<0.05,{ }^{* *} p<0.01,{ }^{* * *} p<0.001$ 
Women: Individual level: Robustness checks, non-parametric association
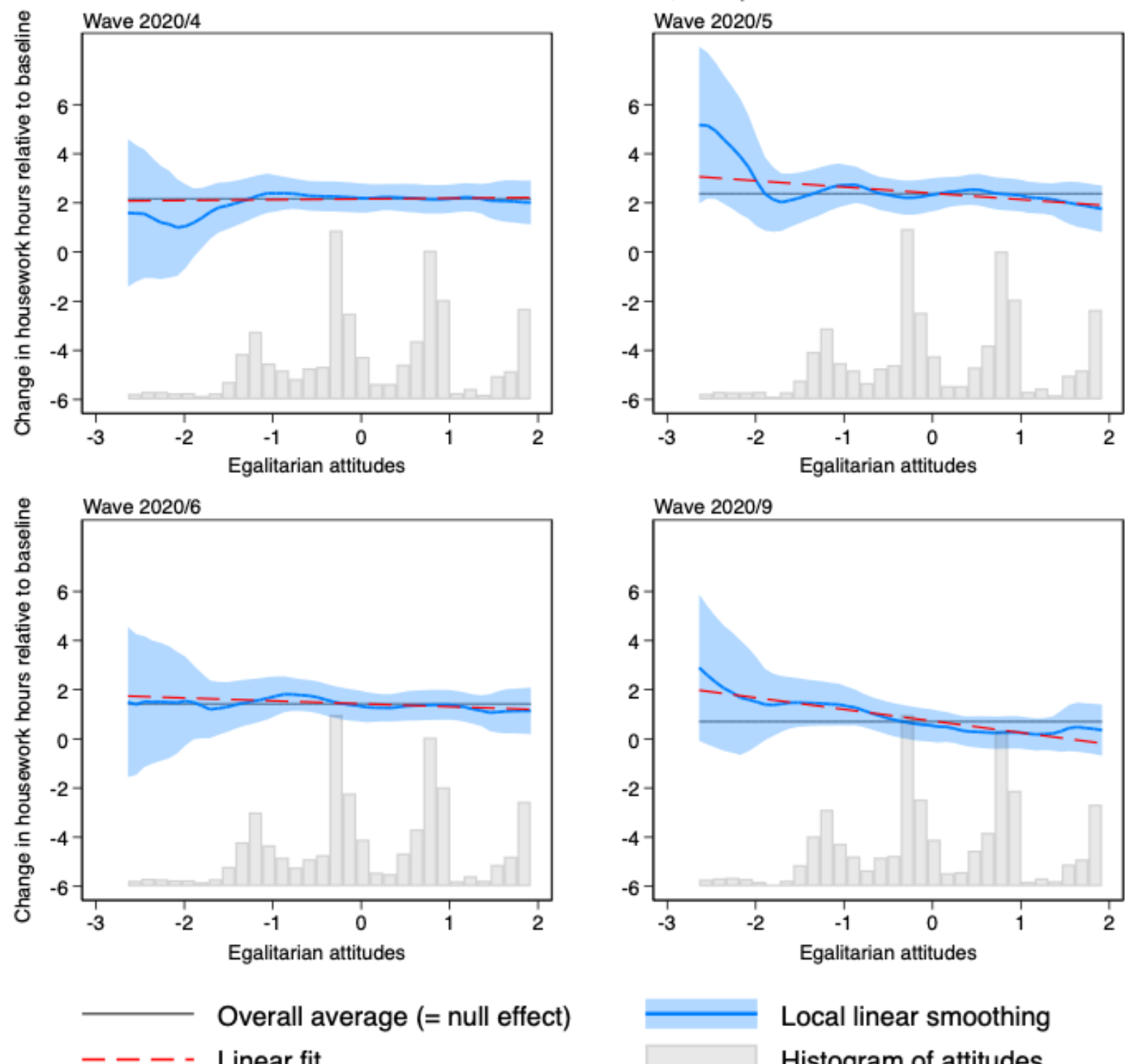

- - - Linear fit

\section{Local linear smoothing \\ Histogram of attitudes}

Fig A1: Examining potential non-linear associations between attitudes and the change in individual housework hours between baseline and the shown COVID-19 wave. Results for women. Local linear smoothing with 95\%confidence intervals is displayed (nobservations: Wave 2020/4 $=2,823$; Wave 2020/5 $=2,382$; Wave 2020/6 $=2,262$; Wave $2020 / 9=2,016$ ). 
Men: Individual level: Robustness checks, non-parametric association
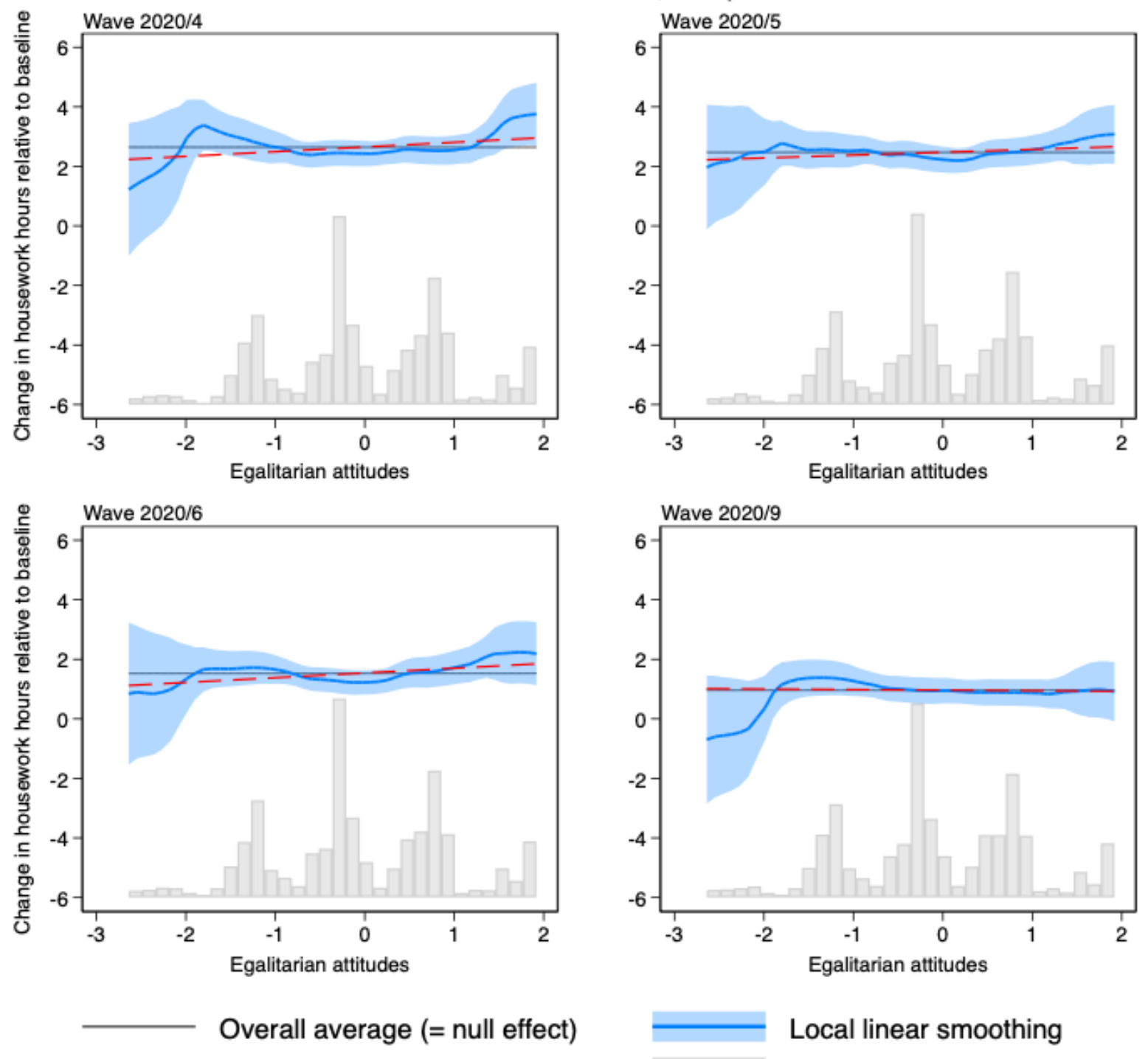

\section{Local linear smoothing Histogram of attitudes}

Fig A2: Examining potential non-linear associations between attitudes and the change in individual housework hours between baseline and the shown COVID-19 wave. Results for men. Local linear smoothing with 95\%confidence intervals is displayed (nobservations: Wave 2020/4 $=2,823$; Wave 2020/5 $=2,382$; Wave 2020/6 $=2,262$; Wave $2020 / 9=2,016$ ). 
Couple level: Robustness checks, non-parametric association with women's attitudes
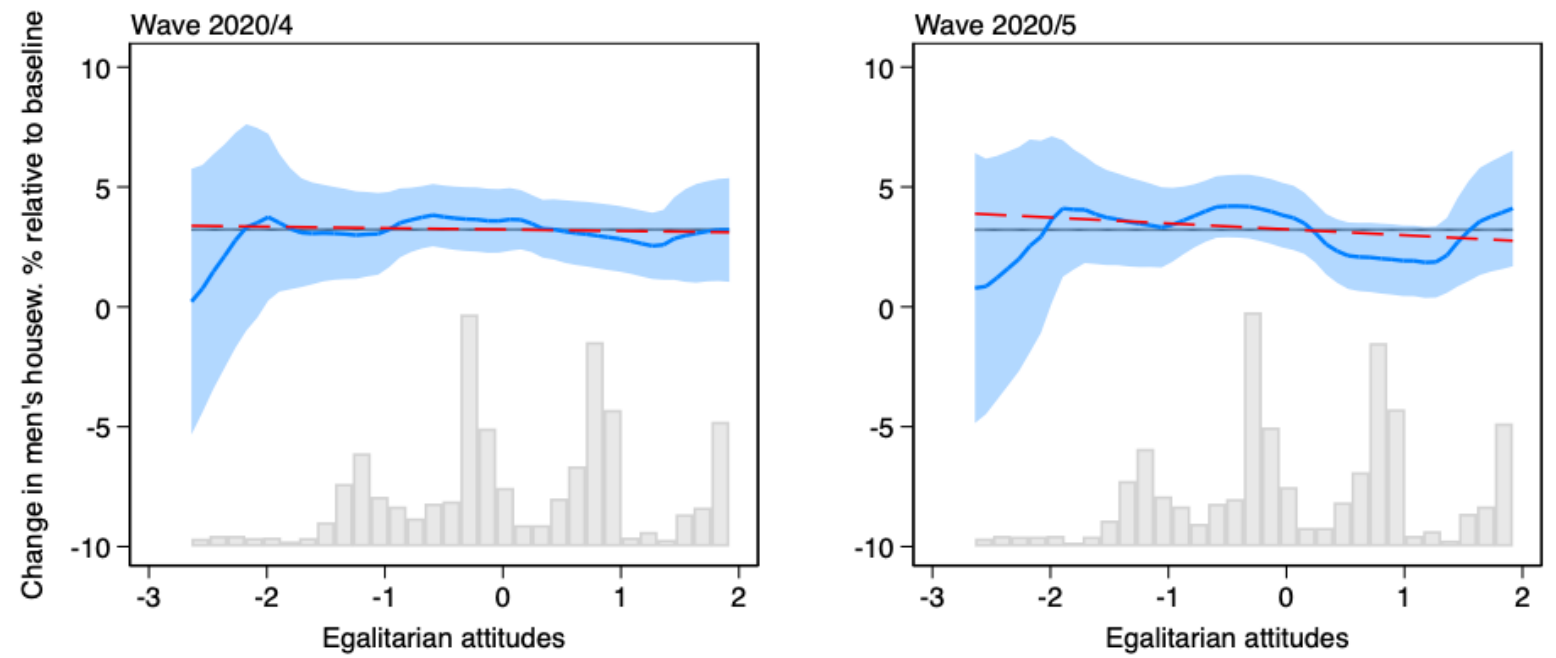

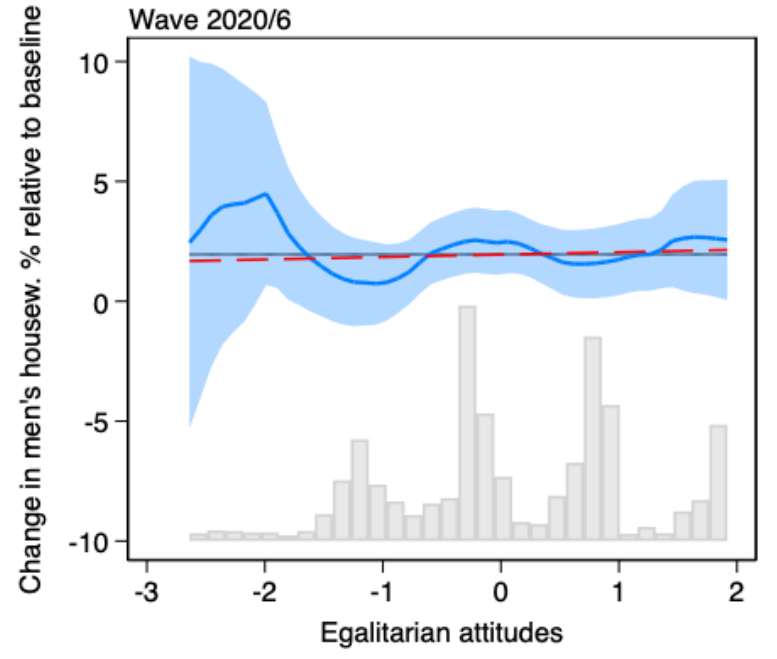

Overall average $(=$ null effect $)$ --- Linear fit

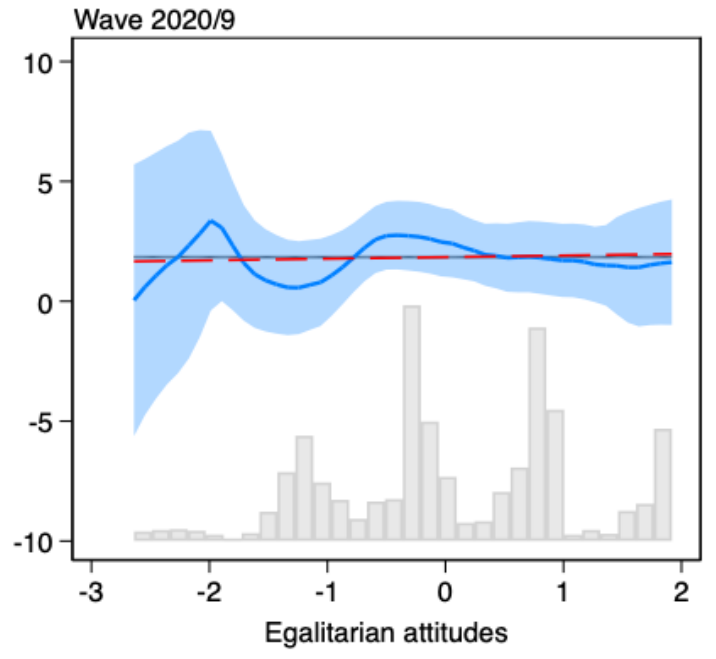

Local linear smoothing

Histogram of attitudes

Fig A3: Examining potential non-linear associations between women's attitudes and the change in men's share of the couple's housework hours between baseline and the shown COVID-19 wave. Local linear smoothing with 95\%-confidence intervals is displayed (nobservations: Wave 2020/4 $=2,823$; Wave 2020/5 $=2,382$; Wave 2020/6 = 2,262; Wave $2020 / 9=2,016$ ). 
Couple level: Robustness checks, non-parametric association with men's attitudes
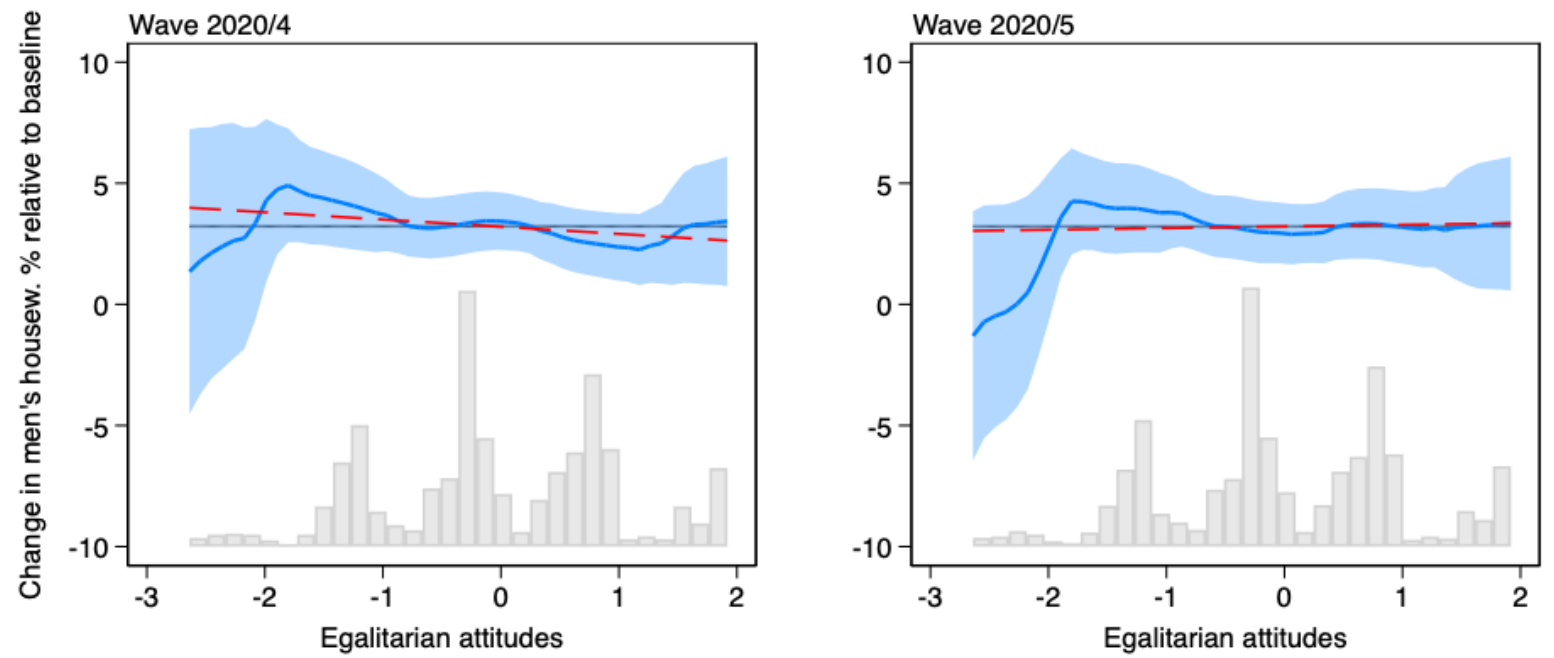

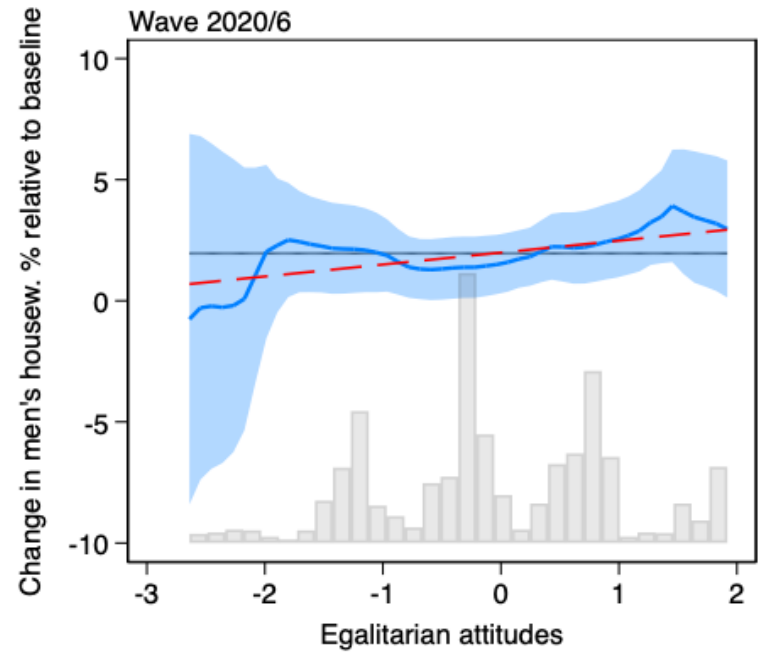

Overall average (= null effect) --- Linear fit

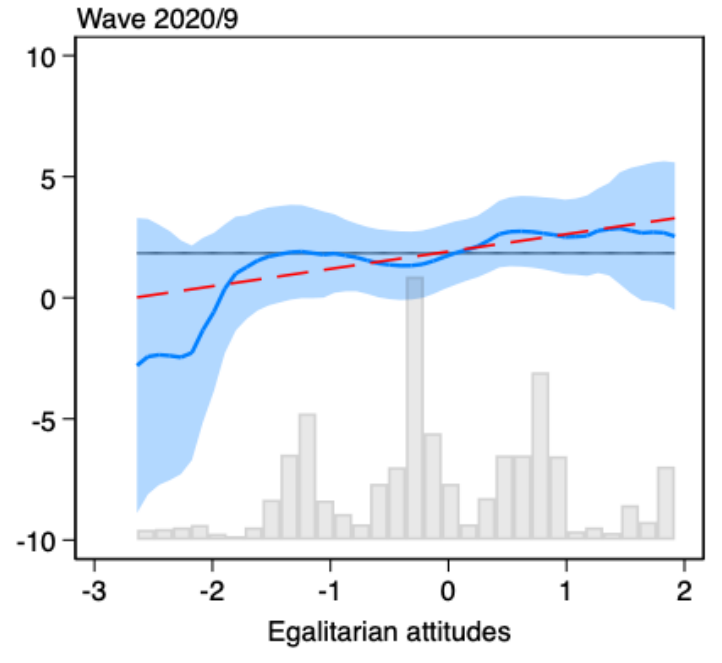

Local linear smoothing

Histogram of attitudes

Fig A4: Examining potential non-linear associations between men's attitudes and the change in men's share of the couple's housework hours between baseline and the shown COVID-19 wave. Local linear smoothing with 95\%confidence intervals is displayed (nobservations: Wave 2020/4 $=2,823$; Wave 2020/5 $=2,382$; Wave 2020/6 $=2,262$; Wave $2020 / 9=2,016$ ). 
Individual level: Robustness checks, recode outliers

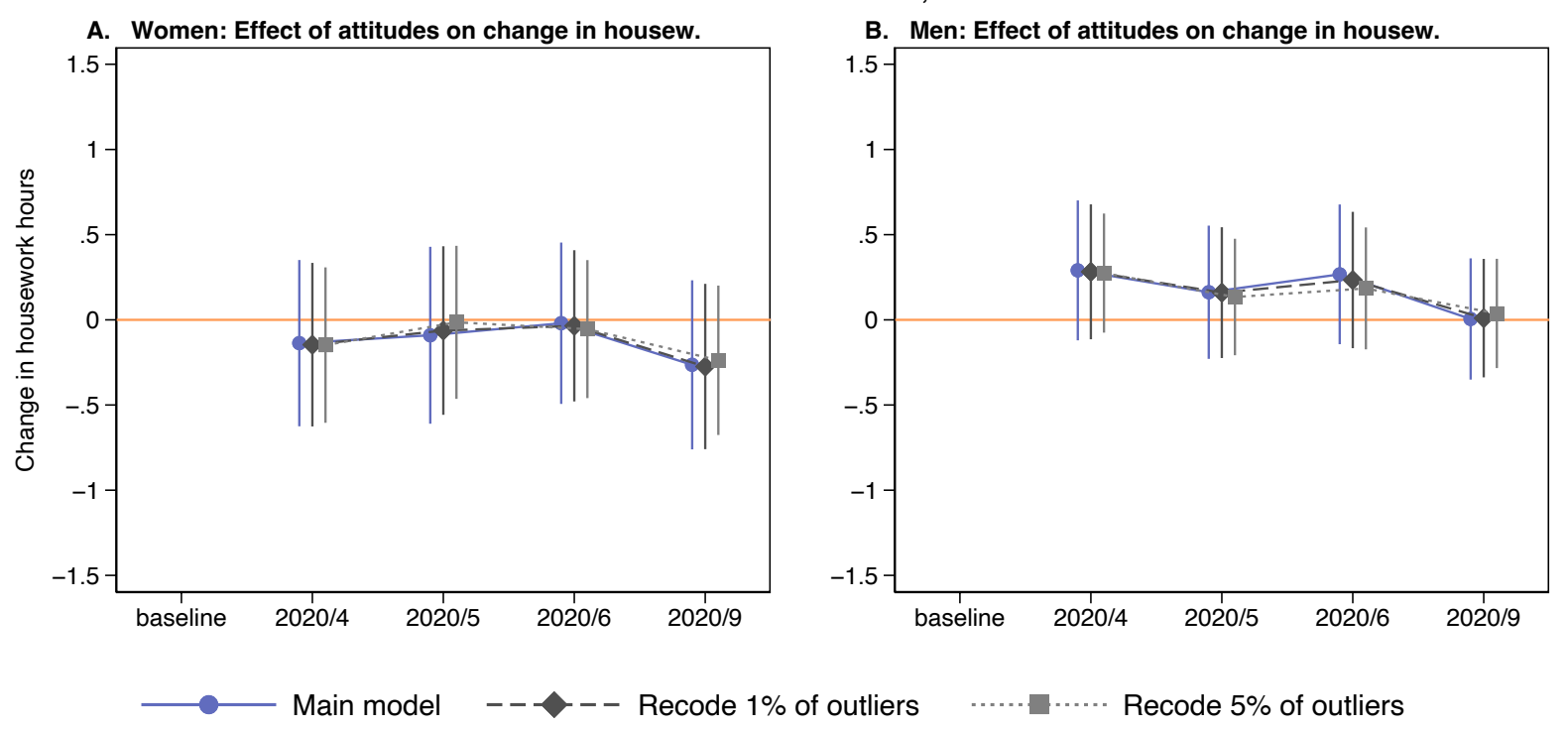

Fig A5: Individual level; examining the role of outliers in the dependent variable ( $\mathrm{n}_{\text {observations: }}$ Wave 2020/4=2,823; Wave 2020/5 = 2,382; Wave 2020/6 = 2,262; Wave 2020/9 =2,016). E.g., recode $1 \%$ of outliers means that, at the upper and lower end of the variable, the $0.5 \%$ of most extreme cases are recoded the 0.5 and $99.5 \%$ percentile.

\section{Couple level: Robustness checks, recode outliers}

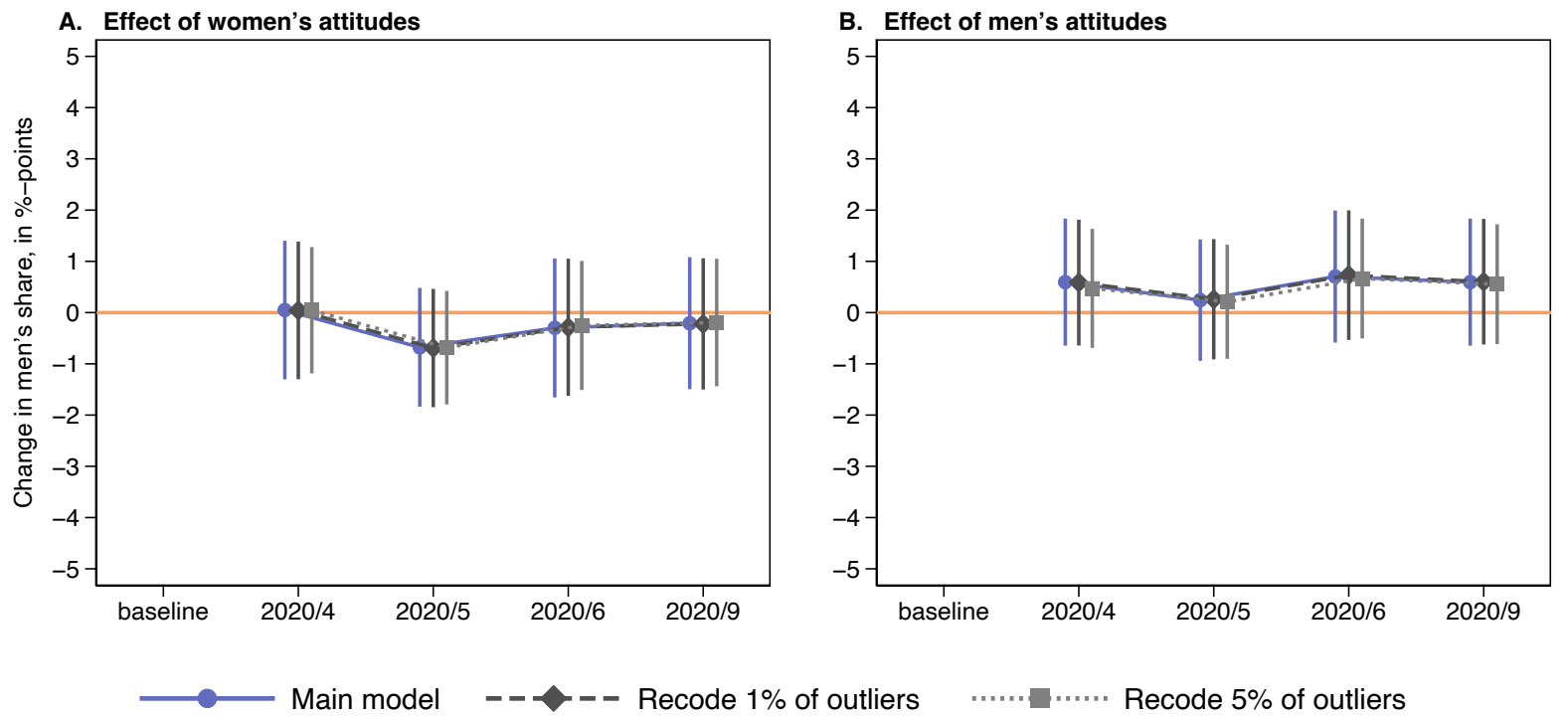

Fig A6: Couple level; examining the role of outliers in the dependent variable (nobservations: Wave 2020/4 = 2,823; Wave 2020/5 = 2,382; Wave 2020/6 = 2,262; Wave 2020/9 =2,016). E.g., recode $1 \%$ of outliers means that, at the upper and lower end of the variable, the $0.5 \%$ of most extreme cases are recoded the 0.5 and $99.5 \%$ percentile. 
Individual level: Robustness checks, add control for income

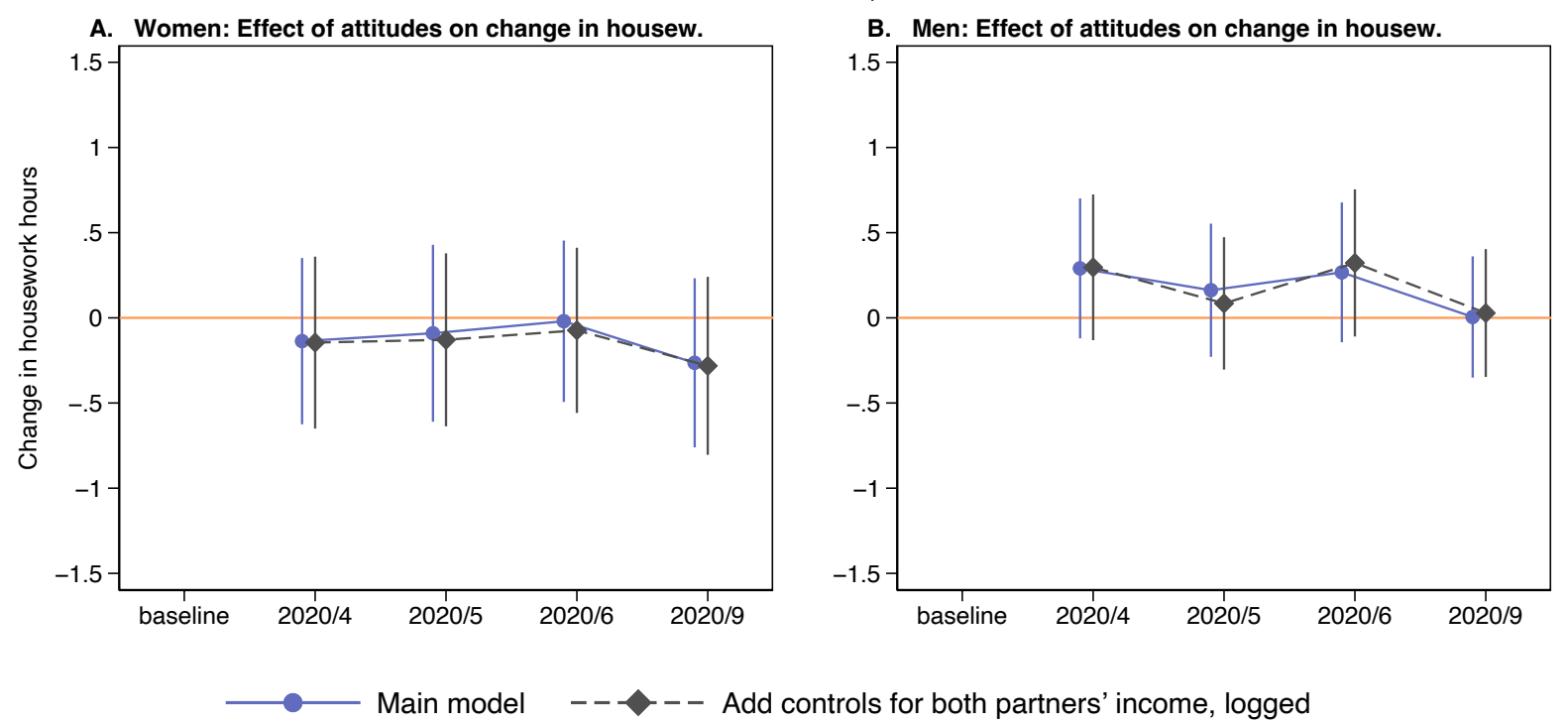

Fig A7: Individual level; additionally controlling for income, logged (nobservations: Wave 2020/4 = 2,635; Wave 2020/5 = 2,205; Wave 2020/6 = 2,080; Wave 2020/9 =1,845).

Couple level: Robustness checks, add control for income

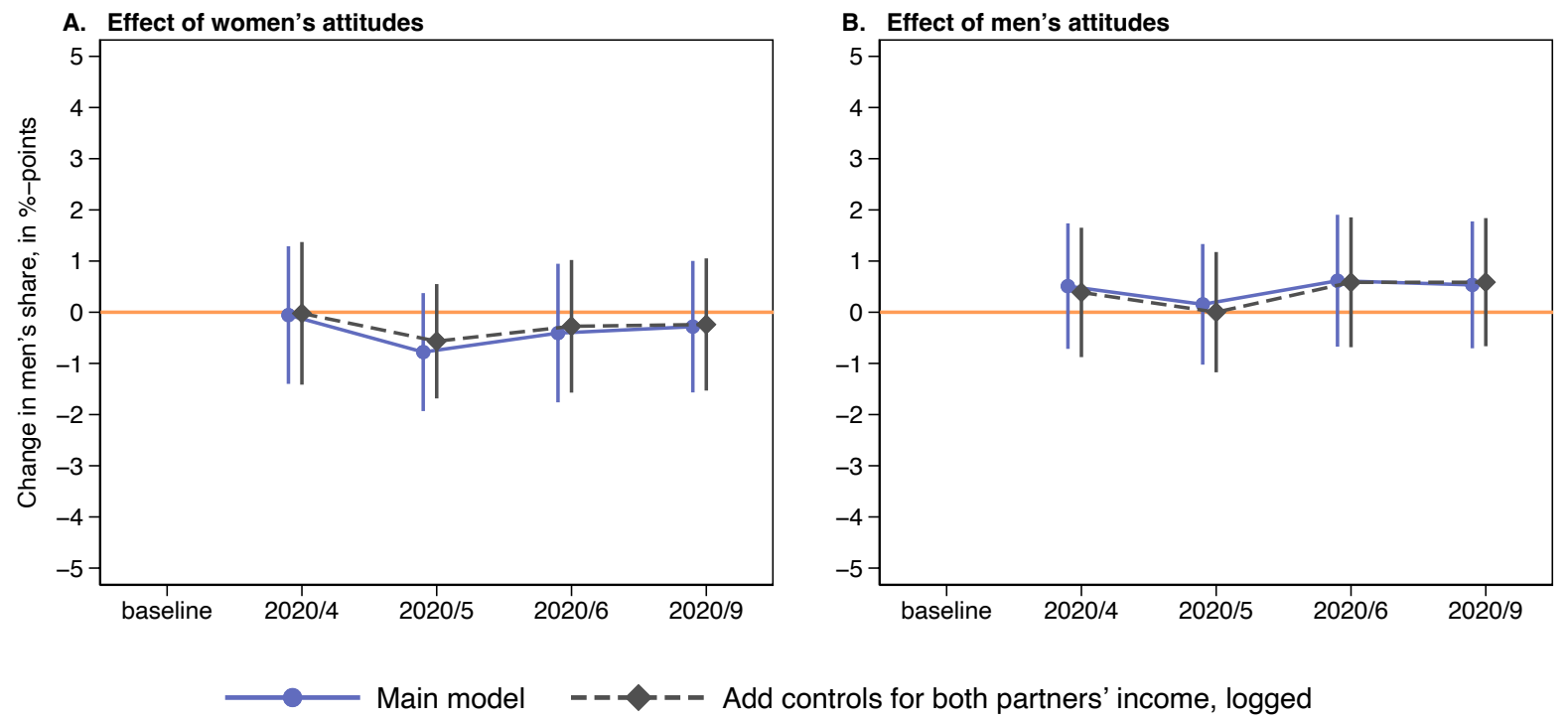

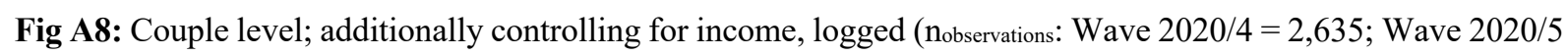
$=2,205$; Wave 2020/6 =2,080; Wave 2020/9=1,845). 